\title{
Failure Mechanism and Control of Lower Retracement Channel in Close-Distance Double-Thick Coal Seams
}

\author{
Fulian He, ${ }^{1,2}$ Kai Lv $\mathbb{D},,^{1,2}$ Xiaobin Li $\mathbb{D},{ }^{1,2}$ Binbin Qin, ${ }^{1,2}$ and Liang Li $\mathbb{D}^{1,2}$ \\ ${ }^{1}$ School of Energy and Mining Engineering, China University of Mining and Technology (Beijing), Beijing 100083, China \\ ${ }^{2}$ Beijing Key Laboratory for Precise Mining of Intergrown Energy and Resources, \\ China University of Mining and Technology (Beijing), Beijing 100083, China \\ Correspondence should be addressed to Kai Lv; 18810179556@163.com
}

Received 14 December 2020; Revised 20 January 2021; Accepted 8 February 2021; Published 27 February 2021

Academic Editor: Mahdi Mohammadpour

Copyright (C) 2021 Fulian He et al. This is an open access article distributed under the Creative Commons Attribution License, which permits unrestricted use, distribution, and reproduction in any medium, provided the original work is properly cited.

Under the condition of close-distance double-thick coal seams' mining, the serious strata behavior occurred in the lower retracement channel, which is affected by the double disturbance with upper coal-pillar static load and mining dynamic pressure. Field investigation, laboratory test, and numerical simulation were used to study the failure characteristics and stress distribution of N0381 retracement channel. The results show that the plastic failure and stress of the surrounding rock are obviously asymmetric; specifically, the closer the roof is to N0381 gob, the stronger the strata behavior is. In addition, when the upper coal pillar is in critical stable or stable state $((w / h)>2)$, high stress concentration in the upper coal pillar is transmitted downward through floor rock so that two dangerous areas with severe strata behavior are formed in N0381 retracement channel. In view of this, a partition control strategy with "high-pressure water jet + asymmetric high-strength cable-beam net + three-hole anchor cable group + roof grouting" as the core is proposed to ensure the stability of the lower retracement channel. This study provides a reference for coal mines with similar production geological conditions.

\section{Introduction}

As an important coal production base in China, Datong coalfield has a long mining history. In recent years, with the continuous increase of mining intensity, the shallow Jurassic coal seams are increasingly exhausted, and the deep coal seams of the Carboniferous-Permian system have been highly valued [1]. The minable coal seams in the Carboniferous-Permian system are characterized by multiple layers, small spacing between layers, and large thickness, thus the close-distance double-thick coal seams are abundant in the Datong mining area [2, 3]. Longwall full-mechanized caving mining technology is widespread in the thick coal seam $(3.5 \mathrm{~m}<$ thickness $\leq 8 \mathrm{~m})[4,5]$. Before moving to a new working face, a large cross-section retracement channel is used for equipment turn and retrace at the stopping line of the old working face [6].

At present, there are two common retracement ways regarding the full-mechanized caving mining working face in China. One is to excavate the retracement channel ahead of time, that is, to excavate 1 or 2 auxiliary passages parallel to the working face at the design stopping line before the end of the mining work [7]. The other is to excavate the retracement channel with the coal cutter. When the working face is pushed to the stopping line, hydraulic supports remain in its position, but the coal cutter and transport machine move forward to cut coal, and finally, a large crosssection retracement channel is formed for equipment recycling $[8,9]$. The preexcavation retracement channel technology sets 4 to 6 connecting roadways between the auxiliary passages, realizing the synchronous relocation of fully mechanized mining (caving) equipment. The preexcavation retracement channel technology has been adopted in Shendong, Ningxia, and other large mining areas. The practice shows that the technology has certain advantages in shortening the time of moving the old working face and installing new one [10]. However, the implementation of the technology has high requirements for the integrity of the 
surrounding rock because the channel is always in a severe dynamic loading state affected by advance abutment pressure [11-13]. The $3 \#$ and $4 \#$ coal seams in the YZS coal mine belong to close-distance double-thick coal seams. Due to the comprehensive effects of upper coal-pillar static load and mining dynamic pressure, a more complex stress superposition evolution is formed during the mining of the lower coal seam. Moreover, the integrity of the surrounding rock is damaged by repeated mining, making the lower retracement channel more difficult to control. Therefore, the applicability of preexcavation retracement channel technology in closedistance double-thick coal seams must be further studied. At present, the method of using the coal cutter to excavate the retracement channel is widely used in Datong coal mine.

According to the geological conditions, coal mining can be divided into single coal-seam mining and coal-seam group mining $[14,15]$. In the past, research studies on the stability of the retracement channel mostly focused on single coal seam with thin (thickness $\leq 1.3 \mathrm{~m}$ ) and medium $(1.3 \mathrm{~m}<$ thickness $\leq 3.5 \mathrm{~m})$ thicknesses [16-18]. There is a lack of research on the failure mechanism and stability control for the lower retracement channel in close-distance double-thick coal seams. In view of this, it is of great practical significance to master the failure mechanism and determine the reasonable support scheme for the retracement channel under the double disturbance of upper coalpillar static load and mining dynamic pressure.

In this paper, the typical close-distance double-thick coal seams in YZS coal mine were chosen as the engineering background. A local model was built to simulate the stability and stress concentration of the upper coal pillar with different aspect ratios. Based on the local model, the failure characteristic and abutment stresses of N0381 retracement channel under the double disturbance of upper coal-pillar static load and mining dynamic pressure were compared and studied in the global model. Furthermore, the stability control strategy for the lower retracement channel was determined to satisfy the geological conditions of closedistance double-thick coal seams and provide reference for the similar coal mines.

\section{Case Study}

2.1. Geological and Mining Conditions. The Yanzishan (YZS) coal mine is located in Datong City, Shanxi Province, China. The 3\# coal seam is being mined at present. Its average buried depth, thickness, and dip angle are $430 \mathrm{~m}, 5.3 \mathrm{~m}$, and $2^{\circ}$, respectively. The N0381 working face in $3 \#$ coal seam adopts longwall full-mechanized caving mining technology, with a mining height of $3.2 \mathrm{~m}$ and a caving height of $2.1 \mathrm{~m}$. Its strike and tendency length are $2517 \mathrm{~m}$ and $180 \mathrm{~m}$. The 4\# coal seam is located above $3 \#$ coal seam, and its average thickness and dip angle are $7.5 \mathrm{~m}$ and $3^{\circ}$, respectively. The average distance between the two coal seams is $25 \mathrm{~m}$, and there is a key layer that is mainly composed of mediumcoarse sandstone, as shown in Figure 1. In addition, a $37.5 \mathrm{~m}$-wide coal pillar was left between N0481 and N0482 gobs, and the horizontal distance between the coal pillar and N0381 tailgate is $30 \mathrm{~m}$ (Figure 2). The method of using the

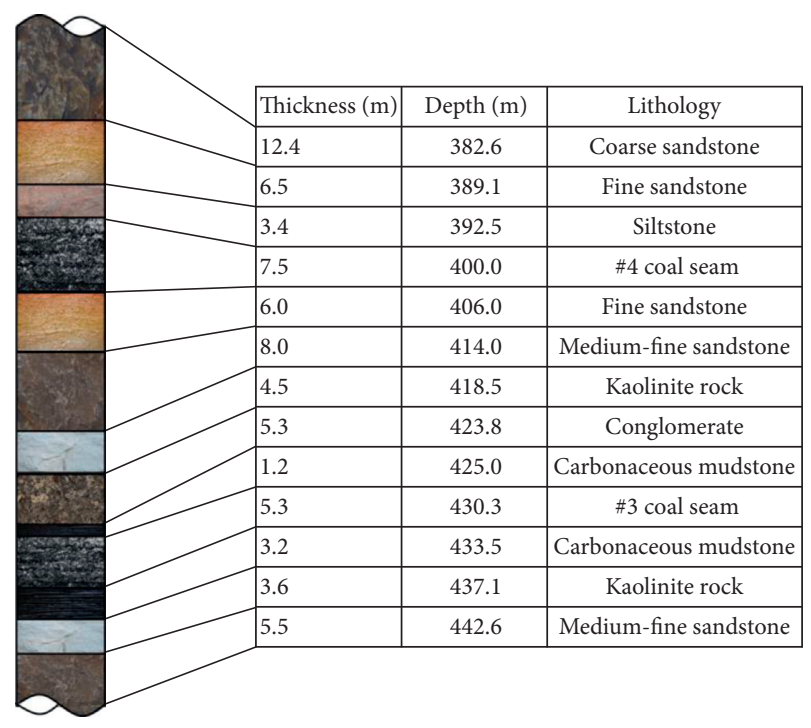

FIgURE 1: Stratigraphic column at the study site.

coal cutter to excavate the retracement channel is used to withdraw equipment at the end of the mining work. N0381 retracement channel section is rectangular with a width of $10 \mathrm{~m}$ and a height of $3.3 \mathrm{~m}$.

2.2. Previous Support Scheme. To evaluate the rationality of previous mining experience in YZS coal mine, field investigation was carried out on N0481 retracement channel in 4\# coal seam. The cables with diameter of $17.8 \mathrm{~mm}$ and length of $6300 \mathrm{~mm}$ were used in the roof, and the cables were connected in rows by w-steel tapes. The spacing of the cables installed in the roof was $1300 \mathrm{~mm} \times 1500 \mathrm{~mm}$, which is a typical uniform and symmetrical arrangement. The bolts with diameter of $18 \mathrm{~mm}$ and length of $1700 \mathrm{~mm}$ were used in the rib, and their spacing was $1000 \mathrm{~mm} \times 1500 \mathrm{~mm}$. The support scheme of N0481 retracement channel is shown in Figure 3.

Field investigation found a large area of coal rib spalling and roof falling during the retracement of the N0481 working face. The maximum load of the hydraulic support reached $53 \mathrm{MPa}$, and the corresponding dynamic load coefficient was 1.77. In addition, severe roof subsidence occurred in some areas, which made it difficult to withdraw hydraulic supports (Figure 4). Compared with N0481 working face, N0381 working face is covered with coal pillars and gobs. The complex stress environment will inevitably bring more serious ground pressure behavior, indicating that the previous support experience is not suitable for N0381 retracement channel. In view of this, this paper takes YZS coal mine as the engineering background to study the failure mechanism and stability control of N0381 retracement channel.

\section{Local Model}

3.1. Stress Concentration in the Coal Pillar under Static Load. When mining N0381 working face (after 4\# coal seam was mined for 5 years), the overburden movement caused by $4 \#$ 


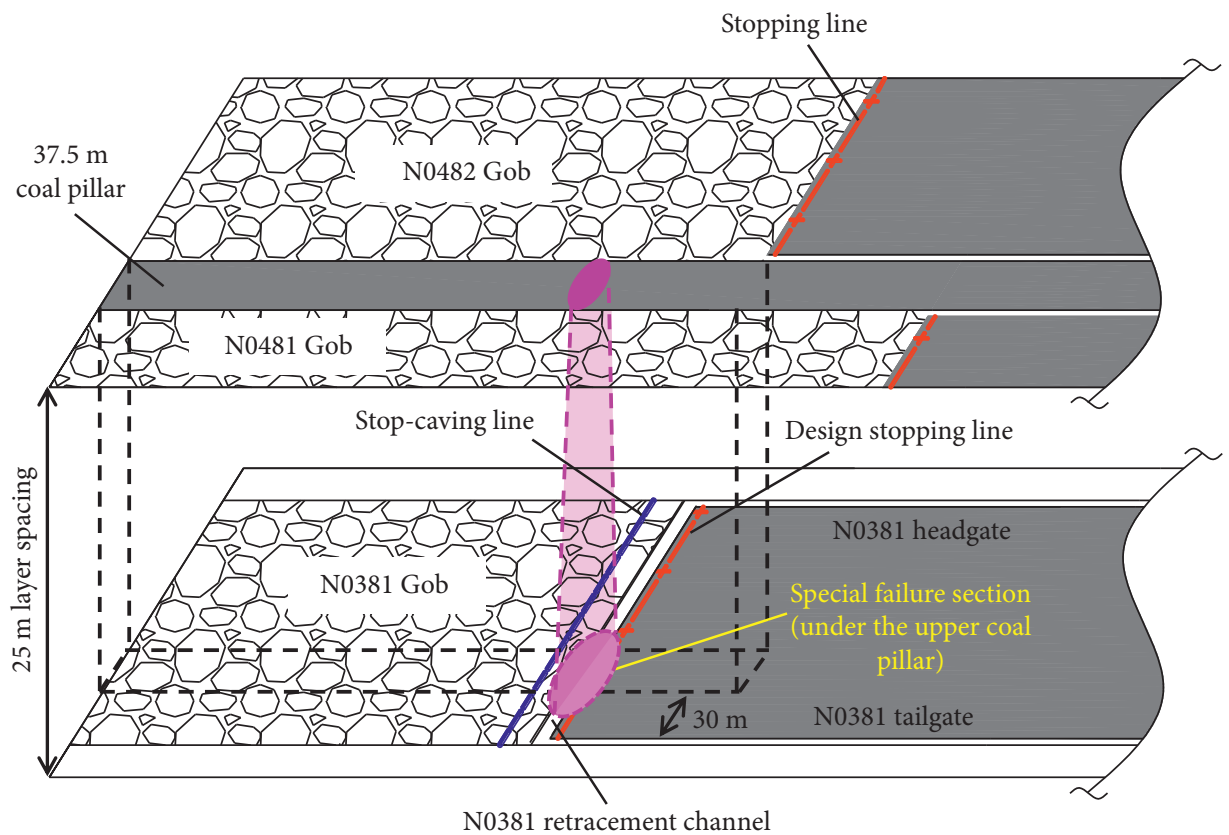

Figure 2: Space location relationship of 3\# and 4\# coal seams.

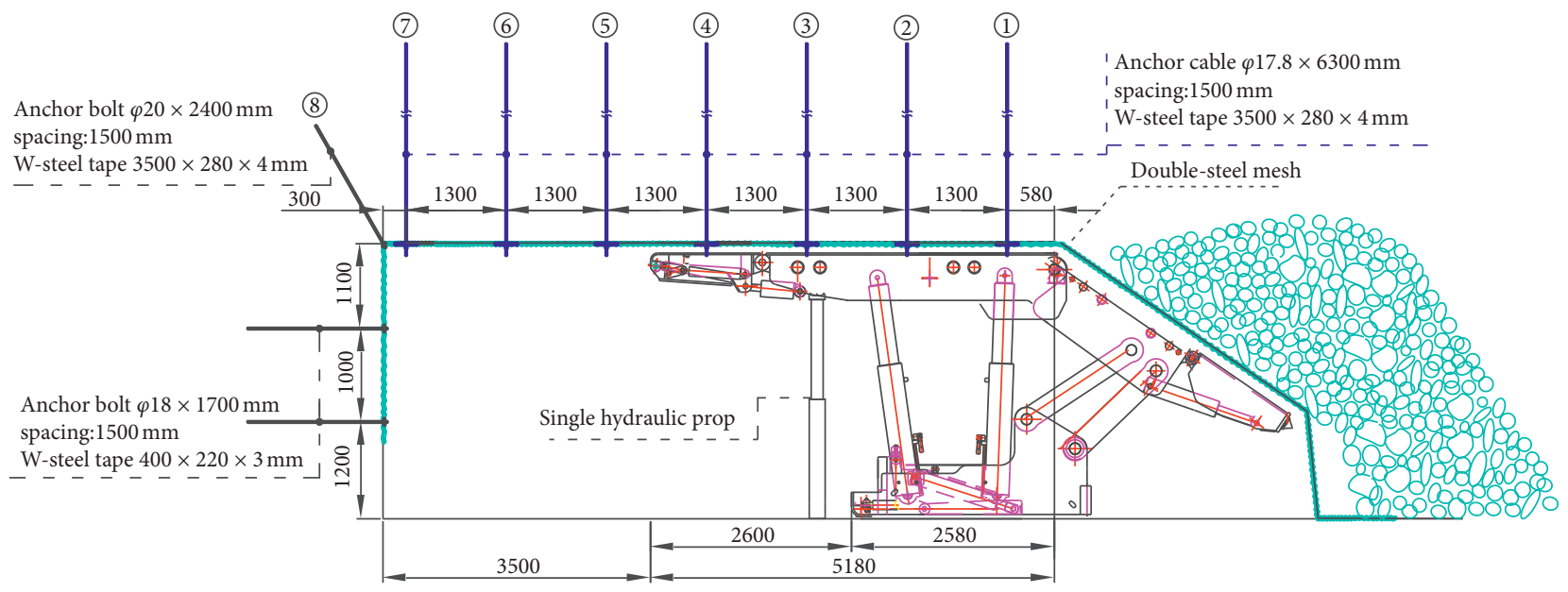

FIgURE 3: Previous support scheme of N0481 retracement channel.

coal seam mining had became stable. It can be considered that the residual coal pillars in 4 \# coal seam were only affected by overlying strata gravity. Under the static load, the stress concentration in the coal pillar with different aspect ratios is different [19]. The different degrees of stress concentration are transmitted downward through floor rock, which has differing impact on N0381 retracement channel.

3.1.1. Principle of Stress Concentration in the Coal Pillar. The premise of studying coal pillar stress concentration is to clarify the stability of the coal pillar. Prassetyo et al. [20] pointed out that coal pillar stability involves pillar load estimation, pillar strength estimation, and safety factor calculation. Once the strength limit of the coal pillar is exceeded by static load, the coal pillar is prone to yield instability. Due to plastic failure is irreversible and the bearing capacity of the plastic zone is limited, thus the residual strength of the yield coal pillar will be greatly reduced. In this situation, the stress concentration in the coal pillar is negatively related to its failure. Specifically, the stress concentration decreases with the increase of coal pillar static load, but increases with the increase of coal pillar strength. However, when the coal pillar is in the stable state, the statement is just opposite. The relationships among coal pillar stress concentration, coal pillar static load, and coal pillar strength are shown in Figure 5. Thus, coal pillar static load and coal pillar strength become the key to clarify the principle of stress concentration in the coal pillar.

3.1.2. The Static Load of the Coal Pillar. When the overlying strata movement caused by N0381 working-face mining tends to be stable, a continuous uniform load is coming on 


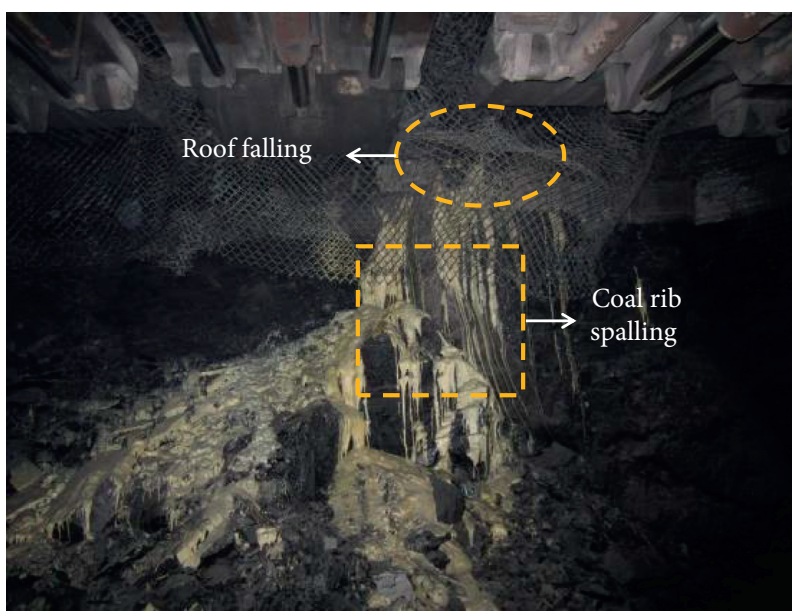

(a)

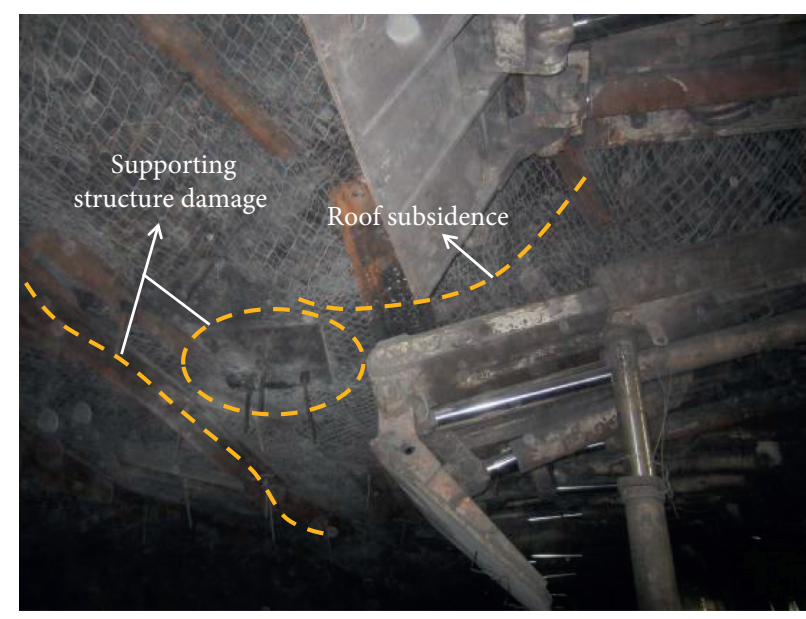

(b)

Figure 4: Deformation and damage of N0481 retracement channel. (a) Coal rib spalling and roof falling. (b) Roof subsidence and supporting structure damage.

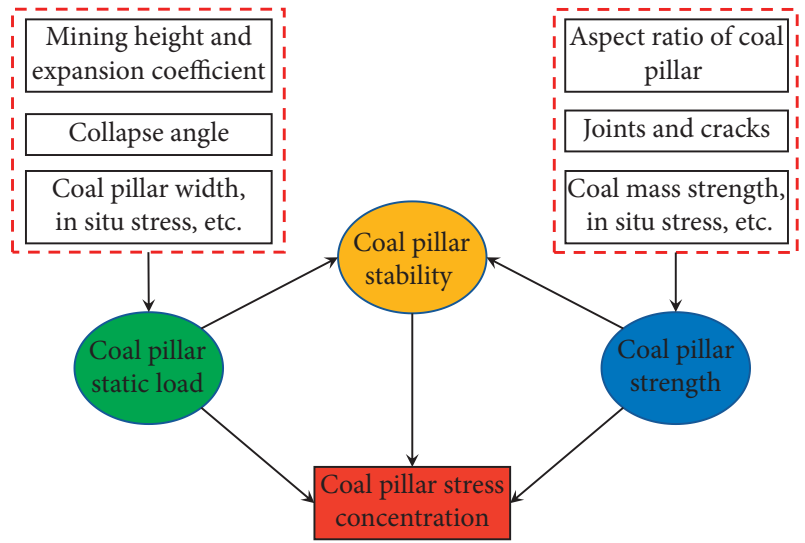

Figure 5: Principle of stress concentration in the coal pillar.

the residual coal pillar, thus this load is static rather than dynamic [21]. The tributary area theory is the most commonly used method for coal pillar static load estimation. The tributary area is defined as the sum of the pillar crosssectional area and excavated area. The theory is based on the assumption that all the strata loads above the tributary area are borne by the coal pillar [22]. As is known to all, longwall full-mechanized caving mining causes the working face to be oversized; such large mining space makes overlying strata collapse fully, so the bearing capacity of gob gangue and floor cannot be ignored. In view of this, the calculation formula for coal pillar static load was obtained by modifying the tributary area.

After the mining of N0481 and N0482 working faces, the overburden of the residual coal pillar developed gradually upward along a collapse angle $(\alpha)$. As shown in Figure 6, the load to be borne by the coal pillar mainly includes two parts: the strata weight $(G)$ within the inverted trapezoid range of the collapse angle and the load $(q)$ transmitted by the higher stable strata.
The geometric relationship (Figure 6) satisfies the following formula:

$$
\frac{\delta}{\sum h}=\cot \alpha,
$$

where $\Sigma h$ is the height of the caving zone, which can be calculated according to $\sum h=h /\left(K_{\rho}-1\right), h$ is the mining height of $4 \#$ coal seam, and $K_{\rho}$ is the expansion coefficient of the caved rocks in the gob.

The strata weight $(G)$ within the inverted trapezoid range of the collapse angle can be expressed as follows:

$$
G=\gamma(w+\delta) \sum h,
$$

where $\gamma$ is the average density of overlying strata and $w$ is the width of the coal pillar.

The load $(q)$ transmitted by the higher stable strata can be calculated as follows:

$$
q=k \gamma\left(H-\sum h-\sum m\right),
$$

where $k$ is the load transfer coefficient of overburden, $H$ is the average depth of $4 \#$ coal seam, and $\Sigma m$ is the cumulative mining height of Jurassic coal seams.

Therefore, the total static load on pillar $\left(L_{p}\right)$ can be evaluated as follows:

$$
L_{p}=\frac{\gamma(w+\delta) \sum h+\gamma k\left(H-\sum h-\sum m\right)(w+2 \delta)}{w} .
$$

If the inverted trapezoid shape of coal pillar overburden is simplified as a rectangle with width of $(w+2 \delta)$ and height of $\Sigma h$, formula (4) can be simplified as follows:

$$
L_{p}=\frac{\gamma k(w+2 \delta)\left(H+((1-k) / k) \sum h-\sum m\right)}{w} .
$$

Due to Jurassic coal seams have been mined for a long time, the cumulative mining height $(\Sigma m)$ cannot be accurately counted. Therefore, borehole stress meters were used 


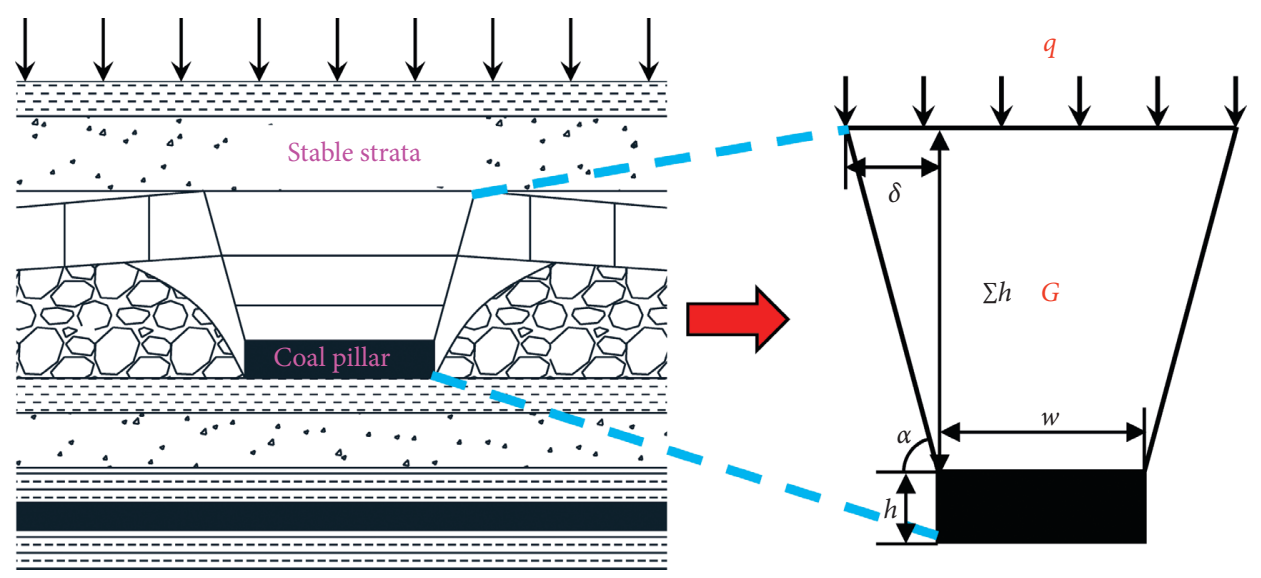

FIgURE 6: Schematic diagram of coal pillar static load.

to monitor in situ stress $\left(S_{1}\right)$ in 4 \# coal seam, and then, formula (5) can be expressed as follows:

$$
L_{p}=\frac{S_{1}(w+2 \delta)}{w} .
$$

Bring formula (1) into formula (6):

$$
L_{p}=S_{1}\left(1+\frac{2 \cot \alpha}{\left(\left(K_{\rho}-1\right) w\right) / h}\right) .
$$

It can be found that the average load of the residual coal pillar is related to the in situ stress $\left(S_{1}\right)$, the collapse angle $(\alpha)$, the expansion coefficient of the caved rocks $\left(K_{\rho}\right)$, and the aspect ratio $(w / h)$. When the mining conditions are determined $\left(S_{1}, \alpha\right.$, and $K_{\rho}$ (kept constant)), the static load of the residual coal pillar is only related to its aspect ratio. Specifically, the static load of the coal pillar increases with the decrease of the aspect ratio $(w / h)$.

3.1.3. The Strength of the Coal Pillar. For the past few decades, an amount of research on coal pillar strength has been conducted using the empirical semistatistical and laboratory test. Salamon et al. [23] suggested an empirical power formula for calculating coal pillar strength with the widthheight ratio as the variable. Bieniawski [24] proposed that when coal pillar size exceeds a critical value, the coal pillar strength will not change with the width-height ratio; thus, the linear formula is more suitable to describe the strength of all sizes of coal pillars. The above empirical analysis methods can be used to predict coal pillar stability on the macrolevel, but it cannot directly show the differing impacts of coal pillar stress concentration on the lower coal seam. However, numerical simulations can achieve the above requirements. Mohan et al. [25] comparatively analyzed failed and stable cases of pillars by FLAC3D and pointed out that numerical simulation may be a feasible and better method to assess coal pillar strength. Esterhuizen et al. [26] put the pillar-roof-floor system as a unit to simulate coal pillars, gob, and overburden response and presented that well-calibrated numerical models can help better understand the load and failure process. In a word, the linear and power formulas indicate that the aspect ratio is a key parameter affecting the strength of the coal pillar. Taking the aspect ratio as a variable, the numerical simulation can visually show the stress concentration of the different sizes of coal pillars, which provides a basis for obtaining the deformation and failure characteristics of the lower retracement channel.

In view of the advantages of numerical simulation, the coal pillar strength was simulated by using the finite difference software FLAC3D in this paper. The specific coal and rock mass parameters, constitutive model, and calibration methods are shown in Section 3.2.

\subsection{Local Model for the Coal Pillar Aspect Ratio}

3.2.1. Model Setup. As a key factor, the aspect ratio is not only affecting coal pillar load but also plays an important role in coal pillar strength. Thus, FLAC3D was used to set up the local model with the aspect ratio as the variable to simulate the stability and stress concentration of the coal pillar. In the local model, the aspect ratio $(w / h)$ of the coal pillar is $1,2,3$, 4 , and 5 , respectively, in which the coal pillar height $(h)$ is $7.5 \mathrm{~m}$. The field observation shows that the expansion coefficient of the caved rocks in N0481 gob $\left(K_{\rho}\right)$ is 1.25 , the collapse angle $(\alpha)$ is $75^{\circ}$, and in situ stress $\left(S_{1}\right)$ is $9.18 \mathrm{MPa}$. Taking these parameters into formula (7), the static load of the pillar can be calculated. Combined with geological conditions, the local model size was $(w+16)$ $\mathrm{m} \times 30 \mathrm{~m} \times 50 \mathrm{~m}$ (Figure 7). The displacements of the model bottom were fixed. The horizontal displacements of the four sides of the model were fixed. Based on in situ stress of $9.18 \mathrm{MPa}$ and rock bulk density of $0.025 \mathrm{MN} / \mathrm{m}^{3}$, a vertical stress of $8.40 \mathrm{MPa}$ was applied to the top boundary of the local model to simulate overburden pressure. Gravity acceleration of $9.80 \mathrm{~N} / \mathrm{kg}$ was applied in the model.

\subsubsection{Rock Mass Parameters and Constitutive Models}

(1) Coal and Rock Mass Parameters. The premise of FLAC3D to successfully simulate coal mine engineering cases is to input reasonable coal and rock mass parameters. Compared with intact rock samples, there are a lot of joints and 

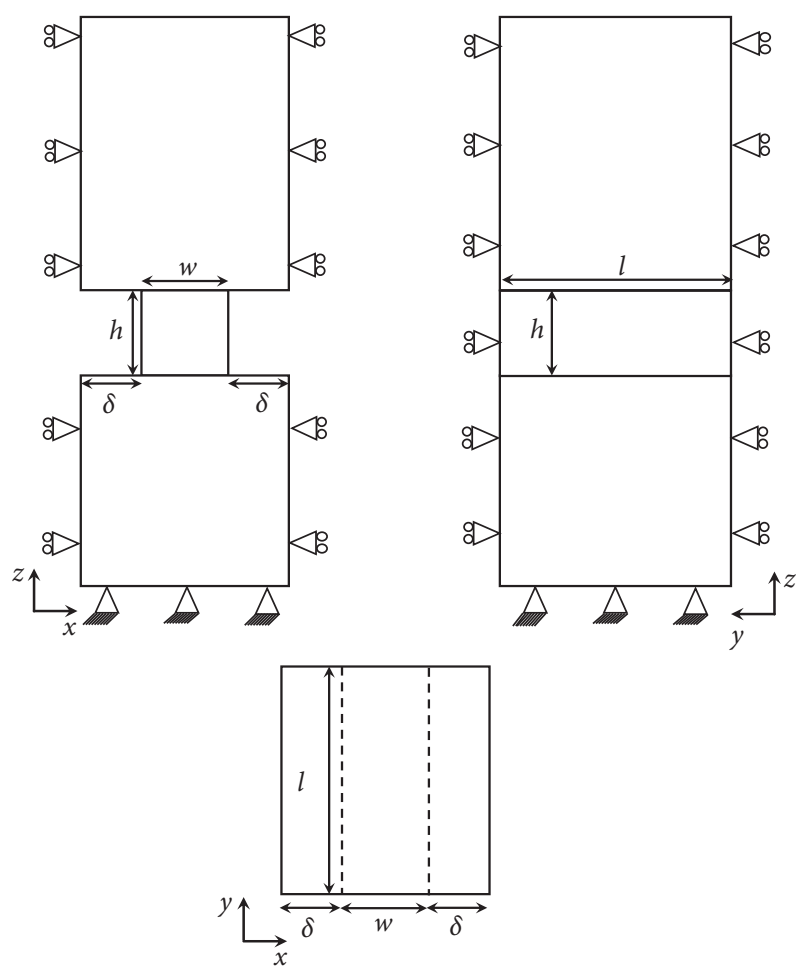

Figure 7: Schematic diagram of the local model. Note: 1 is the width of the local model.

fractures in in situ rock masses. Medhurst and Brown [27] pointed out that joints and fractures could affect the strength of the rock mass, thus the parameters obtained from intact rock by laboratory tests cannot be directly used in numerical simulation. Determining reasonable rock masses' parameters include the following three aspects $[28,29]$ : (a) testing physical and mechanical parameters of the coal and rock mass in the laboratory, (b) translating the intact rock parameters obtained from laboratory tests into rock mass parameters for numerical simulation, and (c) correcting the rock mass parameters by theoretical analysis or on-site measurement.

Based on the nonlinear Griffith failure criterion, the generalized Hoek-Brown criterion was introduced by Hoek and Brown [30]. This criterion could convert laboratory parameters into rock mass parameters by fitting a wide range of triaxial tests on intact rock samples. Therefore, the rock mass strength analysis software RocLab (10.0) was used to determine the parameters of the coal and rock mass in this study. The coal and rock mass parameters obtained are shown in Table 1.

(2) Constitutive Models. The most commonly used constitutive models for the coal seam is the perfect elastic-plastic model and strain-softening model. The strain-softening constitutive model divides the failure process of coal into three phases: elastic phase, plastic phase, and residual phase, as shown in Figure 8. Research and practice show that the strain-softening constitutive model is more in line with the progressive failure process of coal [31]. Thus, the strainsoftening constitutive model was used for $4 \#$ coal seam; in addition, the Mohr-Coulomb constitutive model was used for other strata.

Due to the fact that it is difficult to test the values of the strain-softening model $\left(c_{r}\right.$ and $\left.\varepsilon_{p}\right)$, the evaluation method is usually used to determine the initial values of these parameters, and then, numerical simulation is carried out. Finally, the reasonable parameters are determined by comparing simulation results and field measurement data. The values are listed in Table 2 .

\subsubsection{Local Model Validation}

(1) Theoretical Prediction of Coal Pillar Stability. Because coal pillar stability can truly reflect the relationship between coal pillar strength and coal pillar load, this paper verifies the local model from the perspective of coal pillar stability by using theoretical analysis. Mark and Chase [32] proposed the Mark-Bieniawski formula for calculating coal pillar strength:

$$
S_{p}=S_{1}\left[0.64+\frac{0.54 w}{h}-\frac{0.18 w^{2}}{h L}\right],
$$

where $L$ is the strike length of the coal pillar.

The safety factor (FOS) for evaluating the stability of coal pillars is defined as follows:

$$
\mathrm{FOS}=\frac{S_{p}}{L_{p}},
$$

where the coal pillar load $\left(L_{p}\right)$ and the coal pillar strength $\left(S_{p}\right)$ are determined by formulas $(7)$ and $(8)$ :

$$
\mathrm{FOS}=\frac{S_{p}}{L_{p}}=\frac{0.64+\left((0.54 w / h)-\left(0.18 w^{2} / h L\right)\right)}{1+\left(2 \cot \alpha /\left(K_{\rho}-1\right) w / h\right)} .
$$

The strike length of the coal pillar is more than 2000 $\mathrm{m}(L>>w)$, thus the formula can be simplified as follows:

$$
\mathrm{FOS}=\frac{S_{p}}{L_{p}}=\frac{(0.64+0.54 w / h)\left(\left(K_{\rho}-1\right) w / h\right)}{\left(\left(K_{\rho}-1\right) w / h\right)+2 \cot \alpha} .
$$

According to Kushwaha's research [33], when FOS $\geq 2$, the coal pillar can maintain long-term stability; when FOS $=1 \sim 2$, the coal pillar can maintain short-term stability; when FOS $\geq 0.6$, the coal pillar only keeps stable for few days. Based on geological conditions, mining technology, and pillar setting methods in Chinese, the coal-pillar safety factor table was obtained by investigation and statistical studies (Table 3) [34].

According to formula (11) and Table 3 , the safety factor and stability of the coal pillar is determined. Combined with the results of the local model, it can be found that the stability of coal pillar with different aspect ratios obtained from the simulations agrees well with theoretical prediction (Table 4).

(2) Field Measurement of Coal Pillar Stress. In order to verify the local model from the perspective of stress concentration, borehole stress meters were installed in a $37.5 \mathrm{~m}$ coal pillar 
TABLE 1: Rock mass parameters.

\begin{tabular}{|c|c|c|c|c|c|c|c|c|c|c|}
\hline Lithology & $m_{i}$ & $D$ & GSI & $\sigma_{t}(\mathrm{MPa})$ & $E_{m}(\mathrm{GPa})$ & $K(\mathrm{GPa})$ & $G(\mathrm{GPa})$ & $\Phi$ (deg.) & $c(\mathrm{MPa})$ & $v$ \\
\hline Coarse sandstone & 16 & 0.8 & 72 & 0.50 & 21.29 & 11.83 & 8.87 & 48.6 & 2.70 & 0.20 \\
\hline Fine sandstone & 10 & 0.8 & 62 & 0.17 & 8.91 & 5.12 & 3.68 & 35.2 & 1.27 & 0.21 \\
\hline Siltstone & 11 & 0.8 & 64 & 0.17 & 9.47 & 5.85 & 3.85 & 36.1 & 1.32 & 0.23 \\
\hline 4\# coal seam & 5 & 0.8 & 40 & 0.03 & 1.90 & 1.22 & 0.77 & 16.3 & 0.42 & 0.24 \\
\hline Medium-fine sandstone & 12 & 0.8 & 66 & 0.28 & 13.08 & 7.78 & 5.36 & 41.0 & 1.74 & 0.22 \\
\hline Kaolinite rock & 7 & 0.8 & 53 & 0.07 & 4.42 & 2.73 & 1.80 & 25.3 & 0.75 & 0.23 \\
\hline Conglomerate & 14 & 0.8 & 68 & 0.22 & 12.86 & 7.39 & 5.31 & 41.2 & 1.68 & 0.21 \\
\hline Fine sandstone & 10 & 0.8 & 62 & 0.15 & 8.51 & 5.06 & 3.49 & 34.5 & 1.22 & 0.22 \\
\hline Carbonaceous mudstone & 7 & 0.8 & 47 & 0.05 & 3.30 & 2.03 & 1.34 & 23.3 & 0.66 & 0.23 \\
\hline $3 \#$ coal seam & 5 & 0.8 & 33 & 0.01 & 1.20 & 0.77 & 0.49 & 13.2 & 0.31 & 0.24 \\
\hline Carbonaceous mudstone & 7 & 0.8 & 47 & 0.05 & 3.29 & 2.03 & 1.34 & 23.3 & 0.66 & 0.23 \\
\hline Kaolinite rock & 7 & 0.8 & 53 & 0.07 & 4.42 & 2.83 & 1.78 & 25.3 & 0.75 & 0.24 \\
\hline Medium-fine sandstone & 12 & 0.8 & 66 & 0.28 & 13.10 & 7.53 & 5.41 & 41.0 & 1.75 & 0.21 \\
\hline
\end{tabular}

Note: $m_{i}$ is the constant of intact rock, $D$ is the disturbance coefficient, and GSI is the evaluation parameters of fracture rock.

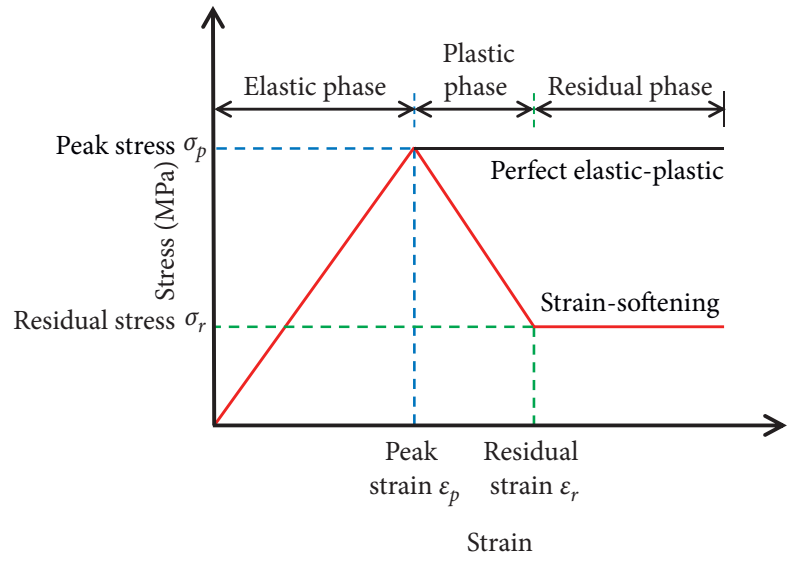

FIGURE 8: Stress-strain relationship.

TABLE 2: Strain-softening parameters.

\begin{tabular}{lcccc}
\hline Properties & $\varepsilon_{p}$ & $\varepsilon_{r}$ & $C_{r}(\mathrm{MPa})$ & $\Phi_{r}\left({ }^{\circ}\right)$ \\
\hline Value & 0.007 & 0.013 & 0.23 & 11.4 \\
\hline
\end{tabular}

Note: $C_{r}$ is residual cohesion and $\Phi_{r}$ is the residual friction angle.

during the mining of N0481 working face. The monitoring scheme is shown in Figure 9(a), and the comparison between field measurement and simulation result $(w / h=5)$ is shown in Figure 9(b). It can be found that the numerical simulation curve is in good agreement with field measurement, which indicates that the rock mass parameters and constitutive model used in the local model are reasonable.

3.2.4. Analysis of Simulation Results of the Local Model. The stress distribution and plastic failure in coal pillars with different aspect ratios $(w / h=1,2,3,4$, and 5) are shown in Figure 10. When the aspect ratio of the coal pillar is 1 , the vertical stress at the top and bottom of the coal pillar is bimodal, but in the middle, it is a single peak. The peak stress is $7.84 \mathrm{MPa}$, which is far lower than in situ stress of $9.18 \mathrm{MPa}$, so the coal pillar is in the pressure relief state. When the aspect ratio is 2, the stress distribution shows an obvious single peak, and peak stress reaches up to $35.03 \mathrm{MPa}$. When the aspect ratio is 3,4 , and 5 , the stress distribution shows double peaks, and peak stress is $21.98 \mathrm{MPa}, 19.70 \mathrm{MPa}$, and $18.68 \mathrm{MPa}$, respectively. It is safe to say that the superposition of the abutment pressure of the coal pillar on both sides decreases with the increase of the aspect ratio. In addition, when the aspect ratio is greater than 2, an elastic core can be found in the center of the coal pillar, and the coal pillar bearing capacity mainly depends on it.

In order to visually show the influence of the aspect ratio on stress distribution and plastic failure, a multivariate analysis method was used to analyze the peak stress, the central stress, the average load, the damage degree, and the horizontal plasticizing depth ratio for the coal pillars with different sizes (Figure 10(f)). The average load, damage degree, and horizontal plasticizing depth ratio are negatively correlated with the aspect ratio. The peak stress and central stress are indexes to characterize the stress concentration of the coal pillar, which are the smallest when the aspect ratio is 1 , reach the peak when the aspect ratio is 2 , and then decrease with the increase of the aspect ratio. This phenomenon shows that there is a critical value $(w / h=2)$ for the coal pillar aspect ratio. When the size of the coal pillar is lower than the critical value, the coal pillar is in an unstable state. Affected by residual strength, the stress concentration in the coal pillar is significantly reduced. When the size of the coal pillar is larger than the critical value, the coal pillar is in a stable state. The superposition of the abutment pressure on both sides of the coal pillar decreases with the increase of the aspect ratio.

\section{Global Model}

4.1. Model Size and Design. The numerical simulation software FLAC3D was used to establish the global model. To realize the principles of plastic failure and abutment stress of N0381 retracement channel, three models with the upper coal-pillar aspect ratio of 1,2 , and 5 were built, corresponding to the upper coal pillar in the unstable state, critical stable state, and stable state, respectively. The global model size was $320 \mathrm{~m} \times 240 \mathrm{~m} \times 72 \mathrm{~m}$. Considering computer 
TABLE 3: Coal pillar safety factor.

\begin{tabular}{lcccc}
\hline Safety factor $(\mathrm{FOS})$ & $0 \leq \mathrm{FOS}<0.8$ & $0.8 \leq \mathrm{FOS} \leq 1$ & $1<$ FOS $\leq 1.5$ & FOS $\geq 2$ \\
\hline Coal pillar state & Unstable & Critical stable & Stable & Absolute stable \\
\hline
\end{tabular}

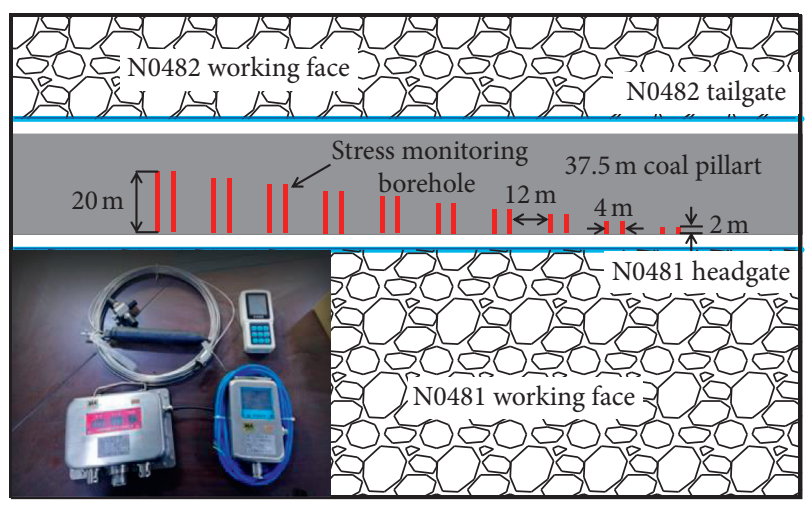

(a)

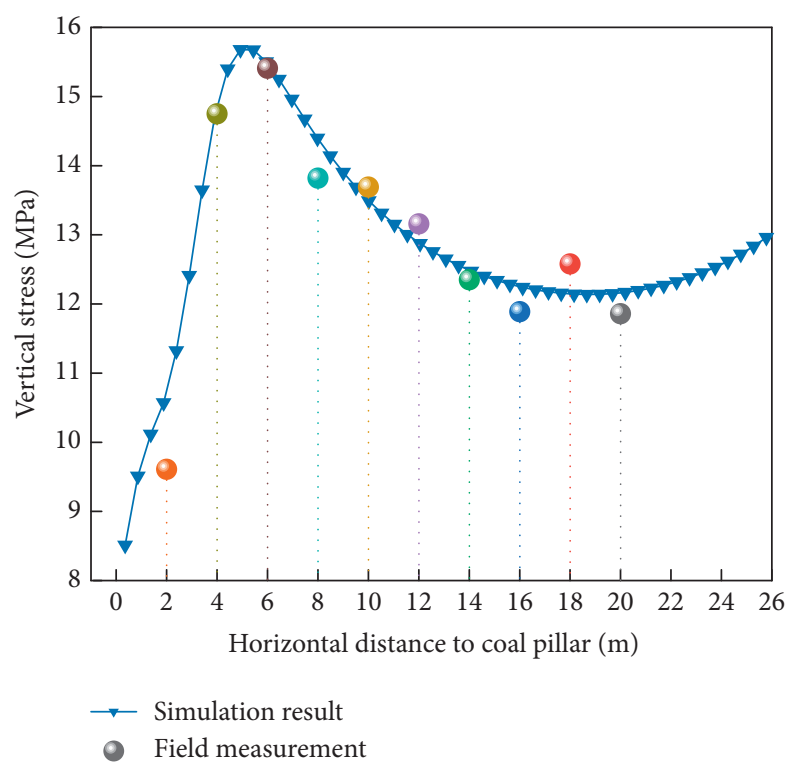

(b)

Figure 9: Comparison between field measurement and simulation result. (a) Layout of field measurement. (b) Field measurement and simulation result.

TABLE 4: Comparison between theoretical prediction and simulation results.

\begin{tabular}{lccc}
\hline Coal pillar aspect ratio & Safety factor (FOS) calculation value & Theoretical prediction results & Simulation results \\
\hline 1 & 0.38 & Unstable & Unstable \\
2 & 0.83 & Critical stable & Critical stable \\
3 & 1.32 & Stable & Stable \\
4 & 1.82 & Stable & Stable \\
5 & 2.34 & Absolute stable & Stable \\
\hline
\end{tabular}

operation efficiency, the grid near the residual coal pillar in 4\# coal seam was refined (Figure 11). The stress boundary condition, displacement boundary conditions, and rock mass parameters were consistent with the local model. A doubleyield constitutive model was used for gob gangue. Strainsoftening and Mohr-Coulomb constitutive models were used for coal seams and other strata (Tables 1 and 2), respectively.

4.2. Double-Yield Model Parameters. Compared with the local model, there are two problems in the global model: (1) after the mining of N0481 and N0482 working faces, how to reasonably control the load of the residual coal pillar to make the global model consistent with the local model, such as coal pillar stress concentration and plastic failure range; (2) with the gap of gob gangue is gradually compacted by overlying rock movement, how to simulate the mechanical properties of gob gangue is another problem to be solved. The double-yield constitutive model is commonly used to simulate the mechanical properties of the gob gangue. Jiang [35] studied the mechanical behavior of gob gangue using the double-yield constitutive model, and the mechanical properties of the caved zone were compared by the theoretical solution and simulation result. Feng and Wang [36] pointed out that the double-yield model obtained data agree well with Salamon's equation, which effectively reflects the loading mechanism of gob gangue. Therefore, setting up a reasonable double-yield constitutive model can effectively solve the above problems.

As an important parameter of the double-yield model, the cap pressure can be calculated as follows [37]:

$$
\sigma=\frac{E_{0} \varepsilon}{1-\left(\varepsilon / \varepsilon_{\max }\right)}
$$

where $\sigma$ is the cap pressure, $E_{0}$ is the initial elastic modulus, $\mathcal{E}$ is the bulk strain of the coal and rock mass, and $\varepsilon_{\max }$ is the maximum bulk strain, and $\varepsilon_{\max }$ and $E_{0}$ can be estimated as follows [38]: 


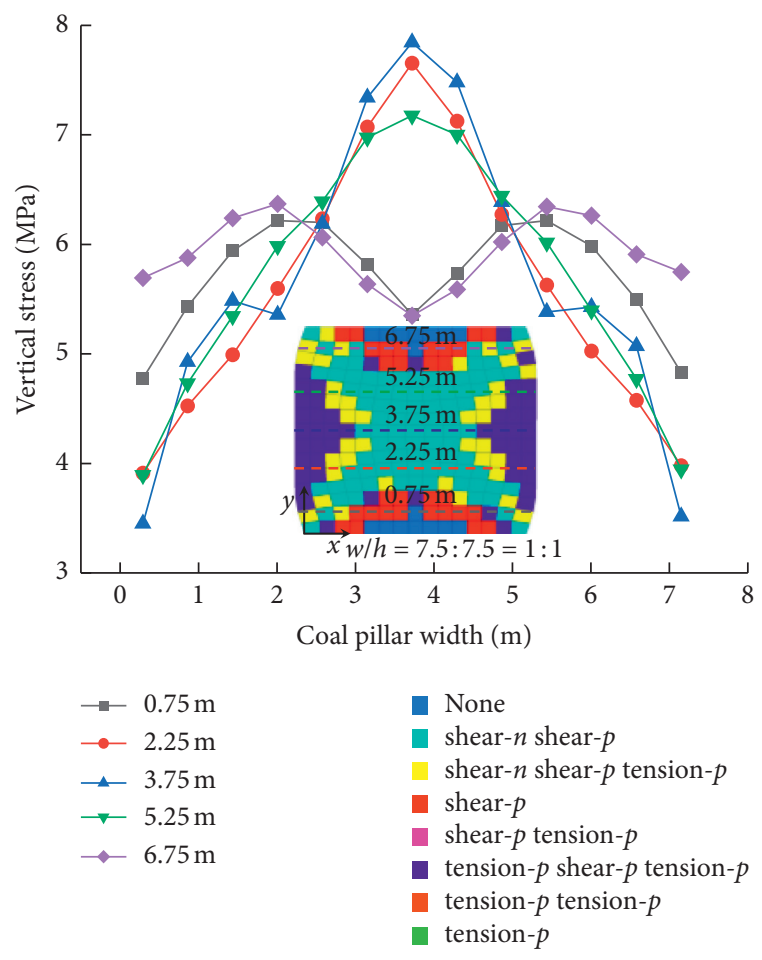

(a)

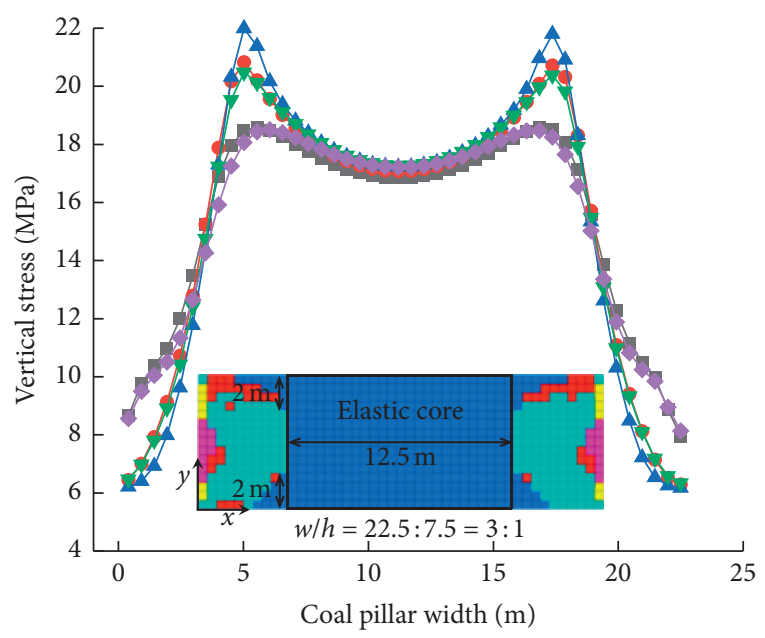

- None

- shear- $n$ shear- $p$

- shear- $n$ shear- $p$ tension- $p$

a shear- $p$

a shear- $p$ tension- $p$

a tension- $n$ shear- $p$ tension- $p$

tension- $n$ tension- $p$

tension- $p$

(c)

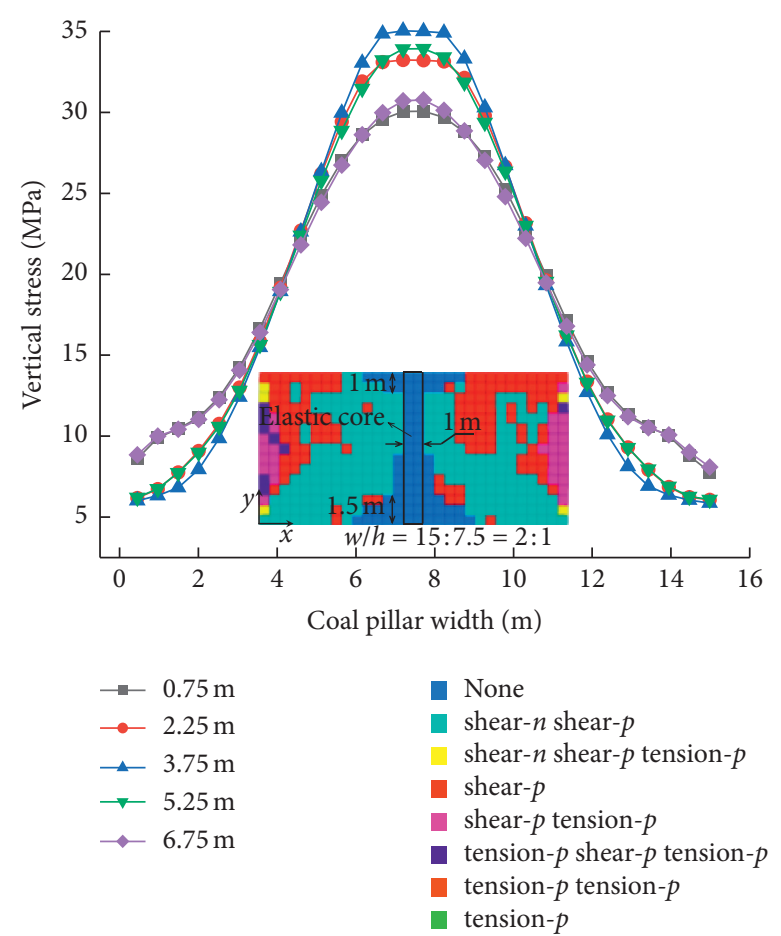

(b)

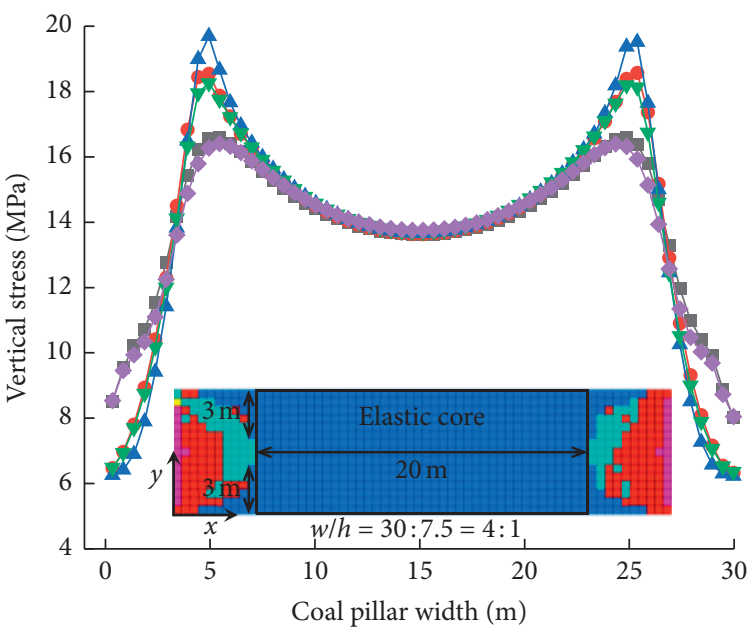

$$
\begin{aligned}
& -0.75 \mathrm{~m} \\
& \multimap 2.25 \mathrm{~m} \\
& \_3.75 \mathrm{~m} \\
& \rightarrow 5.25 \mathrm{~m} \\
& \rightarrow 6.75 \mathrm{~m}
\end{aligned}
$$$$
\text { - None }
$$$$
\text { shear- } n \text { shear- } p
$$$$
\text { - shear }-n \text { shear- } p \text { tension }-p
$$$$
\text { - shear- } p
$$$$
\text { - shear- } p \text { tension- } p
$$$$
\text { a tension- } n \text { shear- } p \text { tension- } p
$$$$
\text { - tension- } n \text { tension- } p
$$$$
\text { tension- } p
$$

(d)

Figure 10: Continued. 


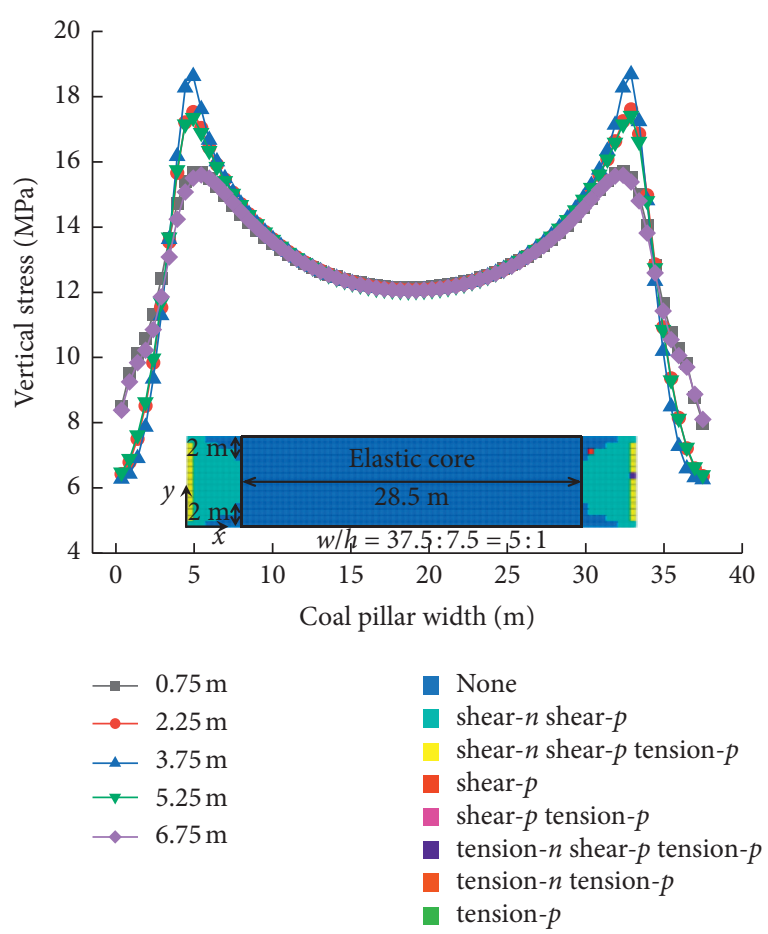

(e)

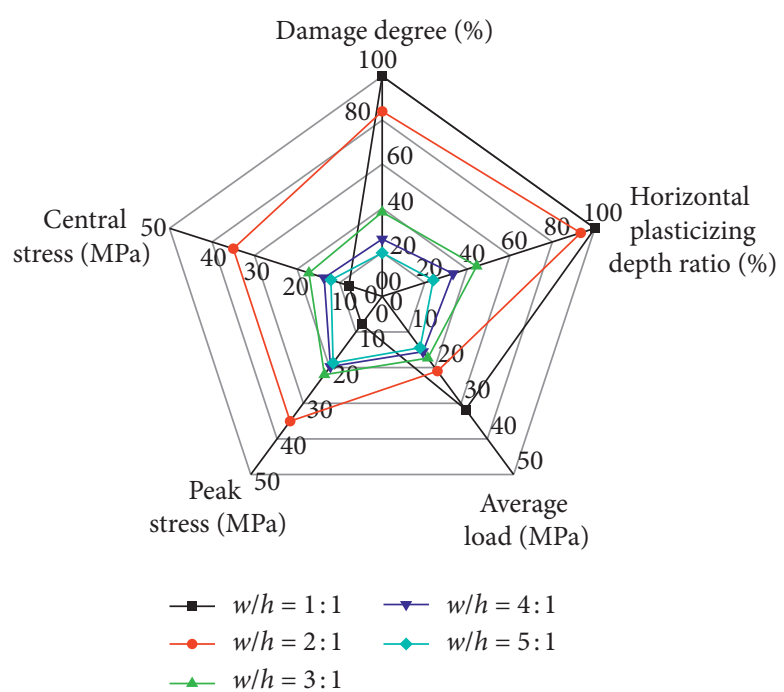

(f)

Figure 10: Stress and failure of the coal pillar with different aspect ratios. (a) Coal pillar aspect ratio of 1. (b) Coal pillar aspect ratio of 2. (c) Coal pillar aspect ratio of 3. (d) Coal pillar aspect ratio of 4. (e) Coal pillar aspect ratio of 5. (f) Multivariate analysis.

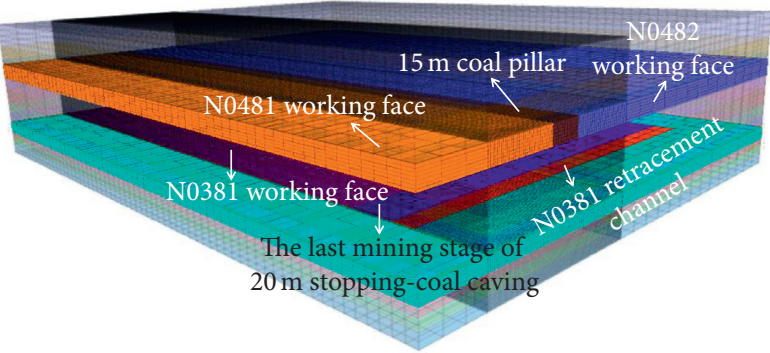

FIGURE 11: Global model (the upper coal pillar with the aspect ratio of 2).

$$
\begin{aligned}
\varepsilon_{\max } & =\frac{\left(K_{\rho}-1\right)}{K_{\rho}}, \\
E_{0} & =\frac{10.39 \sigma_{c}^{1.042}}{K_{\rho}^{7.7}},
\end{aligned}
$$

where $\sigma_{c}$ is the strength of the caved rocks.

Taking N0481 and N0482 gobs in 4\# coal seam as an example, the strength of the caved rocks $\left(\sigma_{c}\right)$ is $23.70 \mathrm{MPa}$, and the expansion coefficient of the caved rocks $\left(K_{\rho}\right)$ is 1.25 . The initial value of cap pressure is calculated by formula (12), and then, the initial parameters were brought into simulation. By using trial and error, the parameter values are constantly adjusted to achieve a good agreement between the global model and local model. The parameters obtained are shown in Tables 5 and 6.
4.3. Global Model Validation. The four indicators (peak stress, central stress, damage degree, and horizontal plasticizing depth ratio) of the coal pillar obtained from local and global models were compared to validate the global model. The stress concentration (peak stress and central stress) and plastic failure (damage degree and horizontal plasticizing depth ratio) of the coal pillars in global models are larger than local models (Figure 12), but the maximum error of each index did not exceed 5\%. From the perspective of safety, it can be said that the high stress concentration of the coal pillar in the global model reserved a safety factor for the lower retracement channel, so the global models and its input parameters can be considered reasonable.

\subsection{Analysis of Simulation Results of the Global Model}

4.4.1. Failure Analyses of the Surrounding Rock. Before N0381 retracement channel formed, a transition distance of $20 \mathrm{~m}$ stopping coal caving was designed to reduce the mining dynamic pressure. Limited by the length of the paper, seven typical sections were selected to study the failure characteristics of N0381 retracement channel, as shown in Figure 13. When the upper coal-pillar aspect ratio is 1, the roof plastic failure is in a shape of "right-angle trapezoid". Specifically, the plastic depth of the roof above the virgin coal rib is $2.2 \mathrm{~m}$. From the virgin coal rib to the central axis of the retracement channel, the roof plastic failure increases linearly, and the plastic depth of the roof near N0381 gob reaches $6.6 \sim 8.8 \mathrm{~m}$. In addition, the failure characteristics of the floor are similar to the roof. Therefore, taking the central axis of N0381 retracement channel as the 
Table 5: Cap pressures.

\begin{tabular}{|c|c|c|c|c|c|c|c|c|c|c|}
\hline Strain & 0.00 & 0.01 & 0.03 & 0.05 & 0.07 & 0.09 & 0.11 & 0.13 & 0.15 & 0.17 \\
\hline Stress $(\mathrm{MPa})$ & 0.00 & 0.53 & 1.78 & 3.37 & 5.44 & 8.26 & 12.34 & 18.76 & 30.30 & 57.23 \\
\hline
\end{tabular}

TABLE 6: Material parameters.

\begin{tabular}{lccccc}
\hline Parameter & $\gamma\left(\mathrm{kg} / \mathrm{m}^{3}\right)$ & $G(\mathrm{GPa})$ & $K(\mathrm{GPa})$ & $\varphi\left({ }^{\circ}\right)$ & $\sigma_{t}(\mathrm{MPa})$ \\
\hline Value & 1340 & 1.15 & 3.74 & 27 & 0 \\
\hline
\end{tabular}

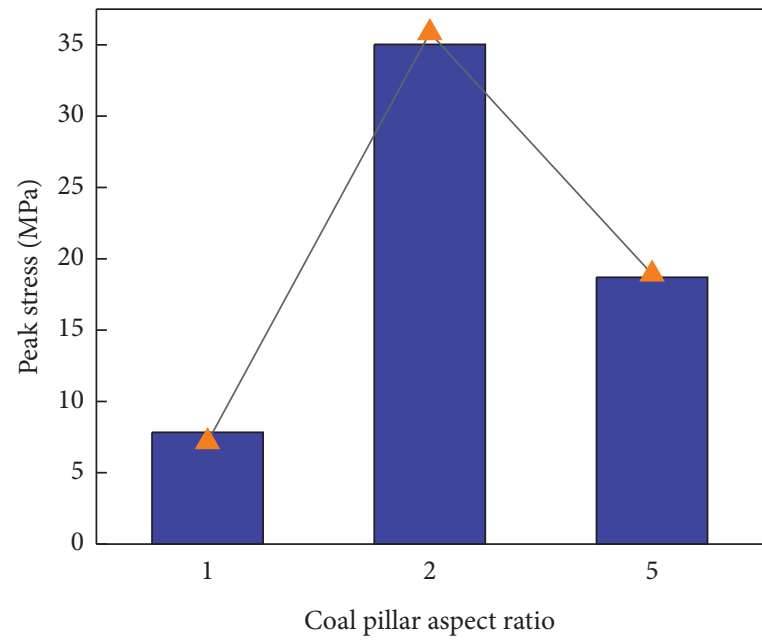

Local model Global model

(a)

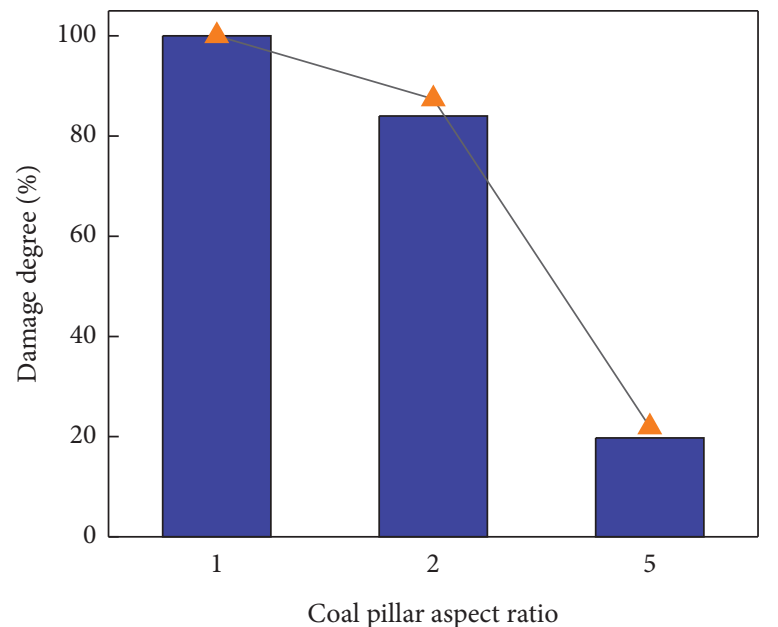

Local model

- Global model

(c)

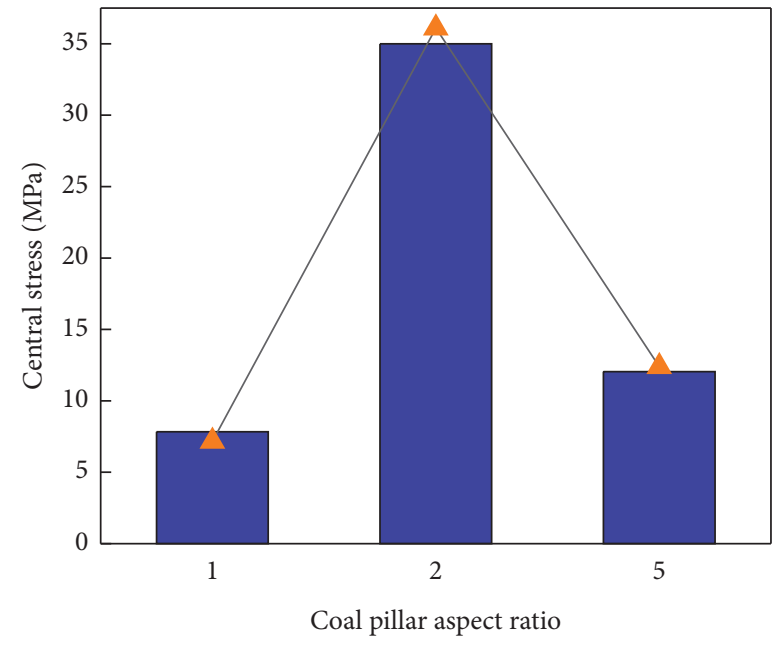

Local model Global model

(b)

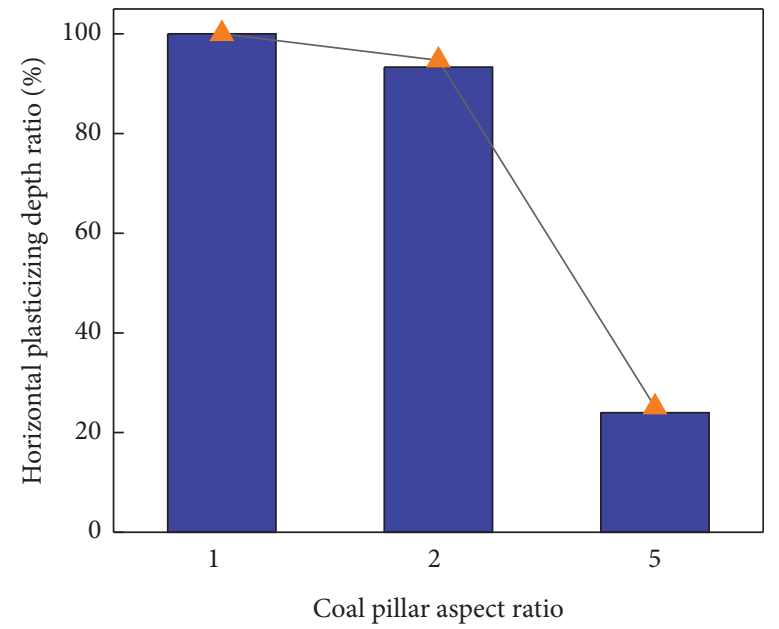

Local model

Global model

(d)

Figure 12: Comparison between local and global models. (a) Peak stress. (b) Central stress. (c) Damage degree. (d) Horizontal plasticizing depth ratio.

boundary, the plastic failure of the surrounding rock is obviously asymmetric, and strata behaviors are mainly concentrated in N0381 gob side. On the contrary, the sections $(y=25$, $31,33,35$, and $43 \mathrm{~m}$ ) that may be affected by the upper coal pillar have no obvious difference compared with other sections $(y=15$ and $58 \mathrm{~m})$ in plastic failure distribution, which indicates that the influence of the upper coal pillar on N0381 retracement channel can be ignored. 

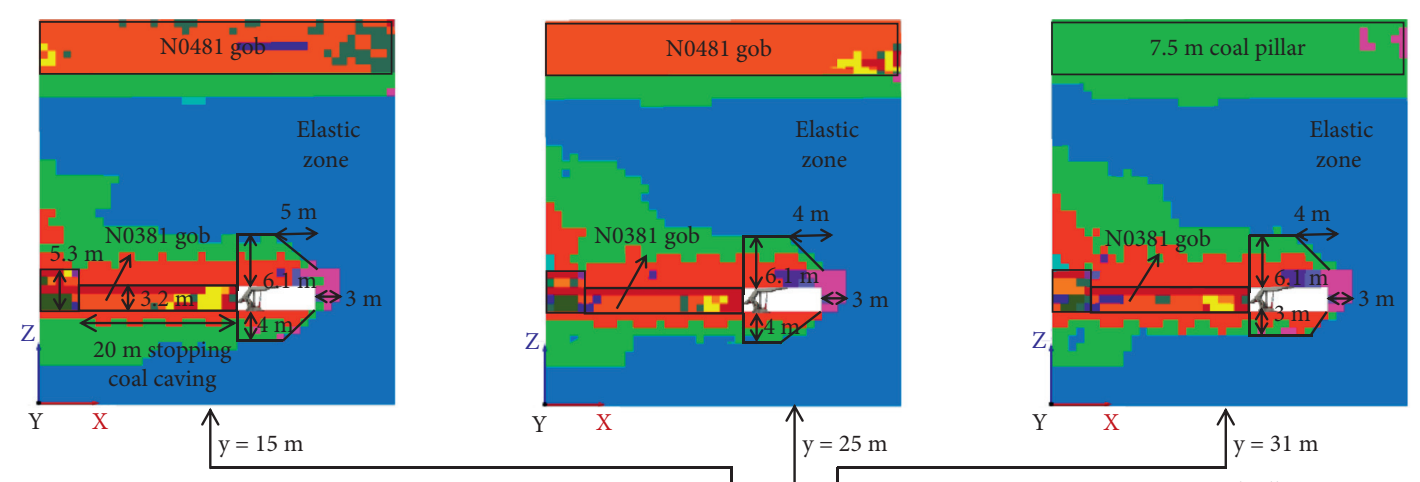

None
shear- $n$ shear- $p$.

shear- $n$ shear- $p$
shear- $n$ shear- $p$ tension- $p$

shear $-n$ shear $-p$ tension $-p$ volume- $n$ volume- $p$

shear- $n$ shear $-p$ tension- $p$ volume- $p$
shear $n$ shear $-p$ volume- $n$ volume- $p$

shear- $n$ shear- $p$ volume- $p$

shear $-n$ tension $-n$ shear $-p$ tension- $p$ volume- $n$ volume- $p$

shear- $p$

shear $-p$ tension $-p$
shear- $p$ tension $-p$ volume-n volume- $p$

shear- $p$ tension $-p$ volume-n
shear- $p$ tension- $p$ volume- $p$

shear- $p$ volume- $n$ volume $-p$

shear $-p$ volume- $p$

tension $-n$ shear- $p$ tension $-p$

tension $-n$ shear $-p$ tension $-p$ volume- $p$

tension- $n$ tension- $p$

tension $-n$ tension $-p$ volume- $p$

tension- $p$

tension- $p$ volume- $n$ volume- $p$

tension- $p$ volume- $p$

volume- $n$ volume- $p$

volume- $p$

- $p$ retrace

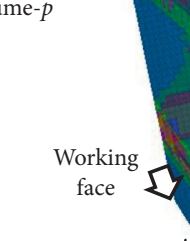

N0381

retracement channel

$$
7.5 \mathrm{~m} \text { coal pillar }
$$

$(\mathrm{y}=30 \sim 37.5 \mathrm{~m})$

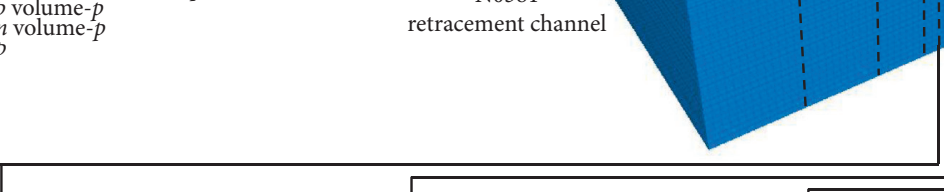

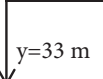

$7.5 \mathrm{~m}$ coal pillar

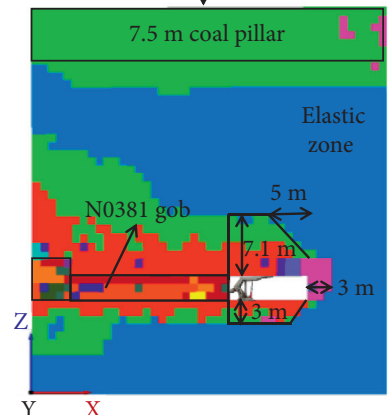

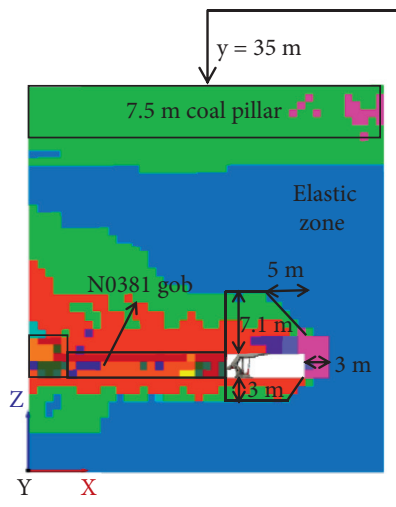

$y=43 \mathrm{~m}$

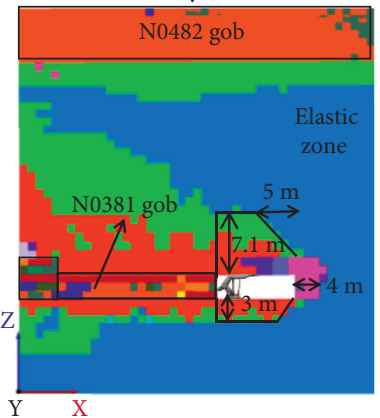

$\mathrm{X}$

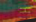

(a)

Figure 13: Continued. 


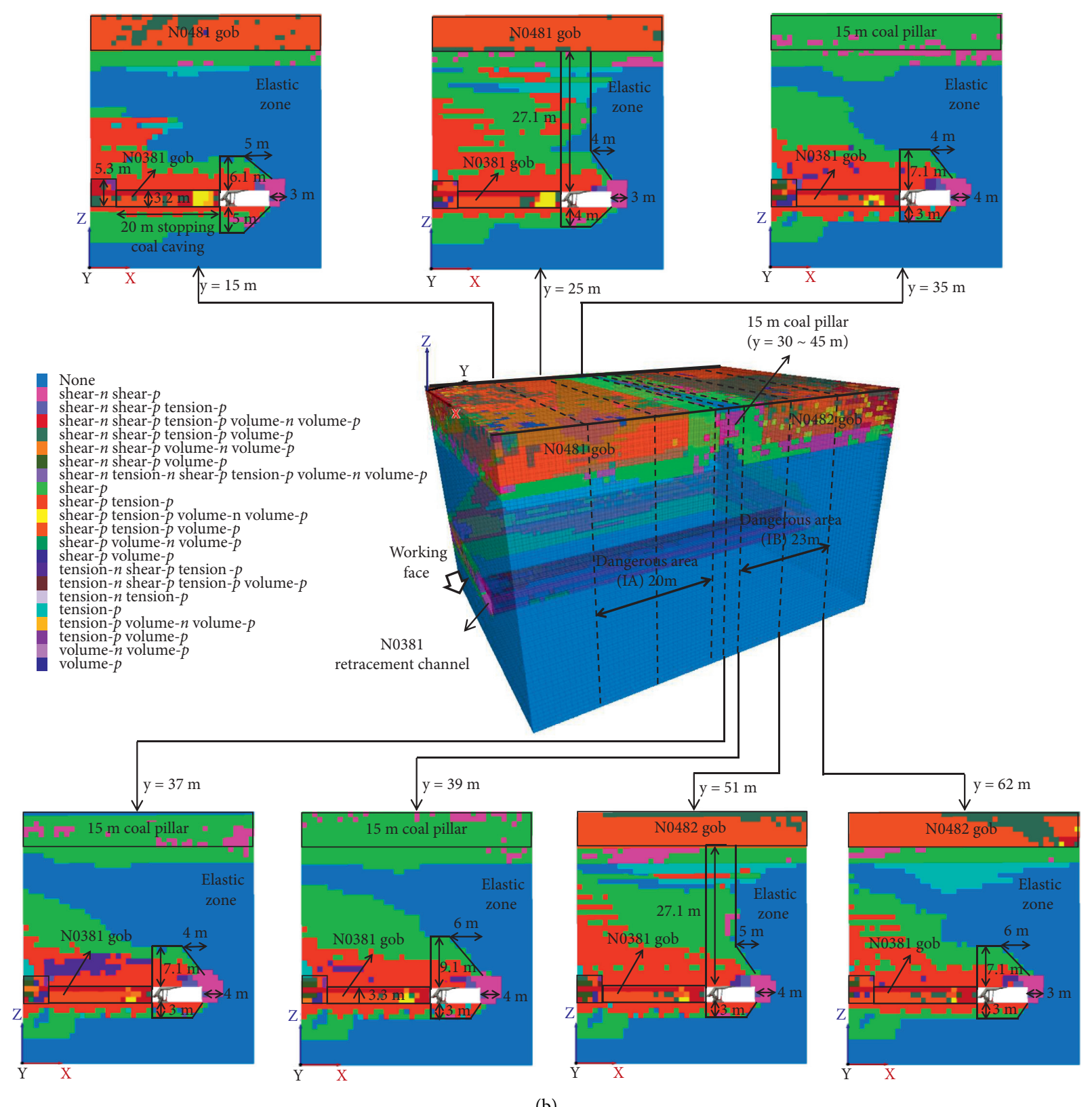

(b)

Figure 13: Continued. 


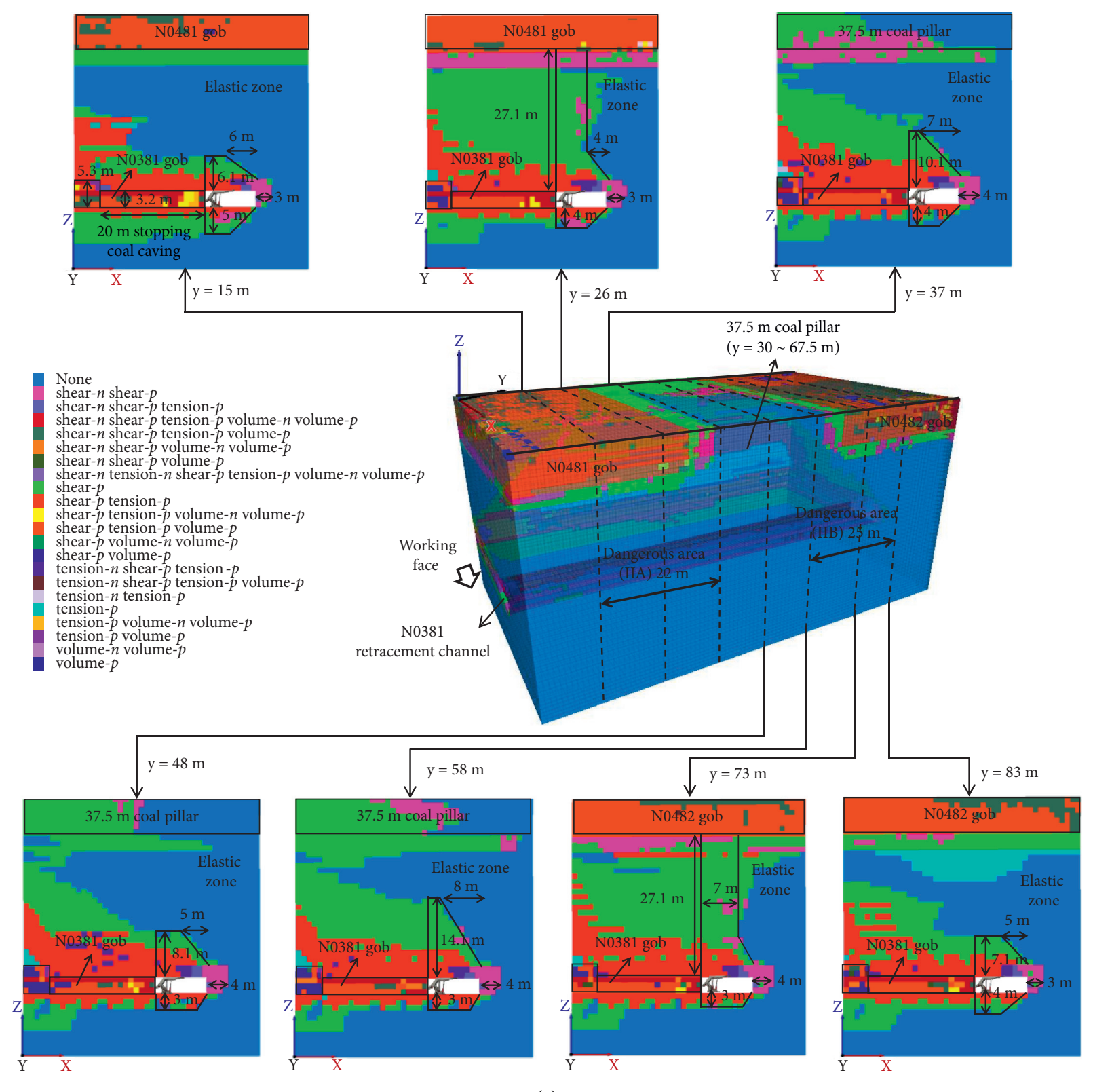

(c)

FIGURE 13: Characteristics of plastic failure of N0381 retracement channel. (a) Upper coal-pillar aspect ratio of 1. (b) Upper coal-pillar aspect ratio of 2. (c) Upper coal-pillar aspect ratio of 5.

When the upper coal-pillar aspect ratio is 2, there are two dangerous areas (I A zone and I B zone) with severe strata behavior under the edges of the upper coal pillar. It can be seen that the range of I B zone is wider than I A zone, specifically, the strike range ( $y$-axis direction) of I A zone and I B zone are 15 35 $\mathrm{m}$ and 39 62 $\mathrm{m}$ (Figure 13(b)). In addition, the plastic failure of surrounding rocks still shows an asymmetric distribution, but the severity of asymmetric strata behaviors in different areas is different. The upper coal-pillar static load and the mining dynamic pressure are coupled and superimposed in dangerous areas (I A zone and I B zone). The double-force sources aggravate the roof damage, and the plastic failure in some sections $(y=25$ and $51 \mathrm{~m}$ ) even develops to the upper gob. Therefore, the asymmetric strata behaviors are more prominent in dangerous areas (I A zone and I B zone). When the upper coalpillar aspect ratio is 5, the failure characteristics of N0381 retracement channel are similar to that of the coal pillar with the aspect ratio of 2 , but the range and damage degree of the dangerous areas (II A zone and II B zone) are slightly larger.

On the whole, the plastic failure of N0381 retracement channel shows an asymmetric distribution; specifically, the plastic depth of the roof near N0381 gob is greater than that of the roof near the virgin coal rib. When the aspect ratio of the upper coal pillar is greater than 2, there are two dangerous areas in the retracement channel, and the plastic failure in those areas is serious and shows stronger asymmetry. In addition, owing to the middle of N0381 
retracement channel is more strongly affected by the mining pressure of N0381 working face, the range of I B (II B) zone is wider than I A (II A) zone.

4.4.2. Abutment Stress Analyses of the Surrounding Rock. In order to clarify the characteristic and principle of the abutment stress in N0381 retracement channel, taking the upper coal-pillar aspect ratio of 5 as an example, the roof stress survey lines were arranged on the typical section $(y=73 \mathrm{~m})$, which was selected from the dangerous area of II B.

As shown in Figure 14(a), the vertical stress of the roof near N0381 gob $(0 \mathrm{~m}<x<5 \mathrm{~m})$ is less than $6.30 \mathrm{MPa}$, indicating that the roof is in the pressure relief state. The vertical stress of the roof increases linearly from the central axis to the virgin coal rib, but the rising speed slows down after entering the virgin coal rib. The peak stress is about $4 \mathrm{~m}$ deep into the virgin coal rib and reaches up to $27.73 \mathrm{MPa}$. Thus, the vertical stress of the roof is asymmetric; specifically, the vertical stress of the roof near the virgin coal rib is greater than that of the roof near N0381 gob. As shown in Figure 14(b), the distribution of horizontal stress at different heights of the roof is different. Specifically, the horizontal stress of the shallow roof (roof height is $1 \sim 6 \mathrm{~m}$ ) increases exponentially and shows obvious asymmetric characteristics; however, the horizontal stress of the deep roof (roof height is $7 \sim 12 \mathrm{~m}$ ) almost keeps a constant value. Therefore, the support design should make full use of the stable horizontal stress environment of the deep roof to compensate the shallow roof.

\section{The Failure Mechanism and Control of the Surrounding Rock}

5.1. The Failure Mechanism of the Surrounding Rock. According to the analysis of plastic failure and abutment stress of N0381 retracement channel, the following two factors should be fully considered for the stability control of the surrounding rocks: the mining dynamic pressure of N0381 working face and the residual coal pillar in 4\# coal seam.

The global models show that the closer the roof is to N0381 gob, the stronger the mining dynamic pressure is, and the plastic failure and stress distribution of the surrounding rocks are asymmetric, evidently with the central axis as the boundary. The severe strata behaviors in the roof near to N0381 gob increases the risk of roof fall, thus huge amounts of pigsty timbering are used to ensure the safe withdrawal of hydraulic supports. Moreover, manual cleaning is often required in the areas with serious gangue caving. The increased workloads not only bring a large amount of material consumption but also make the staff exposed to a dangerous working condition. In addition, after a part of hydraulic supports were withdrawn and once the caved gangue blocks the retracement channel, the ventilation will be adversely affected. In fact, the previous support experience mainly focused on the roof near the virgin coal side and often ignored the role of roof stability above the hydraulic supports.
When the upper coal pillar is in a critical stable or stable state $((w / h)>2)$, the high stress concentration in the coal pillar is transmitted downward through floor rock at a certain angle, resulting in two dangerous areas with severe ground pressure behavior formed in the retracement channel. In the dangerous areas, the upper coal-pillar static load and the mining dynamic pressure are coupled and superimposed. The double-force sources aggravate the roof damage, and thus, the asymmetric strata behaviors are more prominent. Different from single coal-seam mining, the adverse effects of the upper coal pillar on the lower retracement channel should be considered fully in closedistance double-thick coal seams.

\subsection{Stability Control of N0381 Retracement Channel}

5.2.1. High-Pressure Water Jet Technology. In order to avoid the adverse effects of the upper coal pillars on N0381 retracement channel, the critical stable or stable coal pillars $((w / h)>2)$ should not be left in $4 \#$ coal seam. If a wide coal pillar must be left for safety mining, pressure relief measures should be taken to eliminate the stress concentration in the coal pillar. Deep-hole blasting, large-diameter dense holes, and high-pressure water jet are the commonly used pressure relief means in coal mines, which can effectively reduce stress concentration and improve the stability of the surrounding rock $[39,40]$. In view of the advantages of highpressure water jet technology, such as little bit wear, less dust, and no spark, the high-pressure water jet should be preferred [41].

Through continuous rotary cutting inside the coal pillar, water jet boreholes with radius of $d / 2$ are formed. The stress state of the coal mass around the water jet borehole changes from triaxial compressive to uniaxial compressive, forming a plastic circle with a radius of $D / 2$, as shown in Figure 15. With the decrease of the boreholes' spacing $(b)$, the stress curves around the boreholes are superimposed, and the coal mass between the boreholes is more prone to plastic failure. The design principle of the high-pressure water jet scheme is to ensure that the stress field and plastic zone caused by water jet boreholes are superposed to form continuous and effective cutting for the coal pillar elastic core.

5.2.2. "Asymmetric High-Strength Cable-Beam Net + ThreeHole Anchor Cable Group + Roof Grouting" Partition Control Strategy. According to the failure mechanism of N0381 retracement channel, the roof near to N0381 gob was seriously damaged by the mining dynamic pressure, and thus, it is necessary to use the supporting structure to improve the roof adaptability to the asymmetric failure. In addition, when the high-pressure water jet technology affected by geological conditions becomes difficult to implement, the support design should also fully consider the stress concentration of the upper coal pillar.

In view of the above problems, the surrounding rock partition control strategy with "asymmetric high-strength cable-beam net + three-hole anchor cable group + roof grouting" as the core is proposed. (1) The asymmetric 


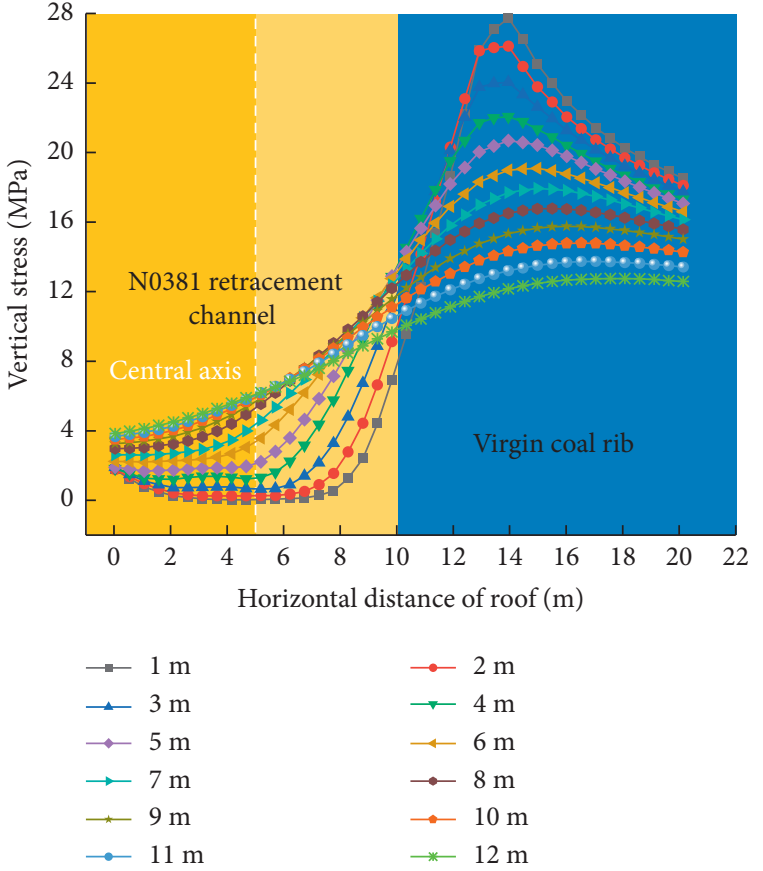

(a)

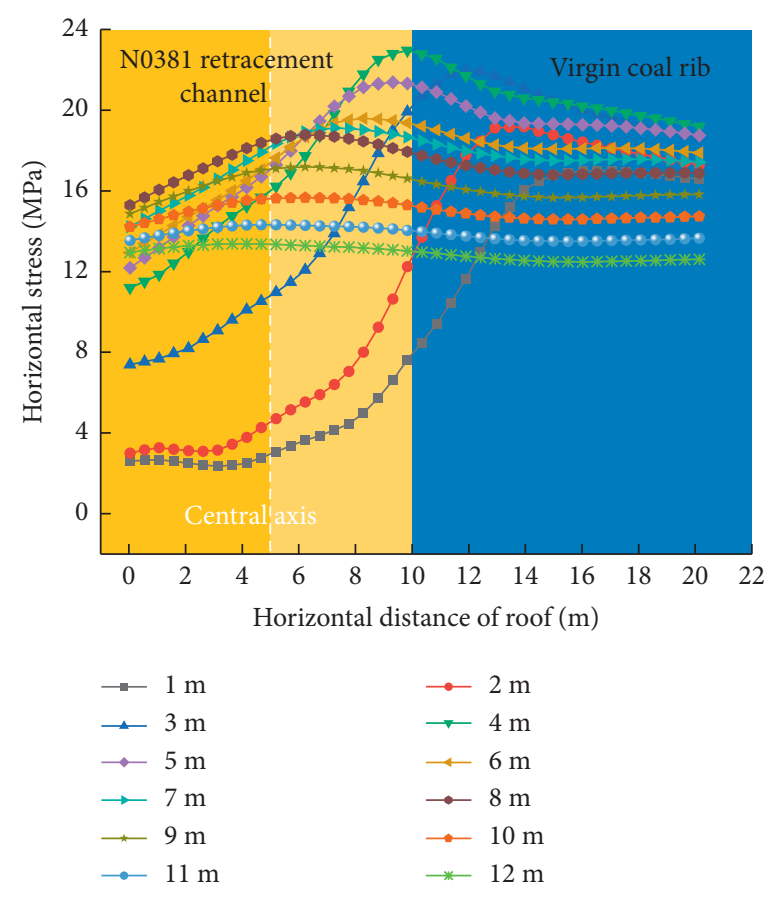

(b)

FiguRE 14: Stress distribution of the roof of N0381 retracement channel. (a) Vertical stress of different heights. (b) Horizontal stress of different heights.

arrangement of high-strength cable-beam net is used to improve roof support strength. Especially, by strengthening the bearing capacity of the roof near to N0381 gob, restricting vertical stress transfer to the virgin coal rib, and weakening the asymmetry of roof stress distribution. (2) The partition support is adopted for N0381 retracement channel, specifically, three-hole anchor cable group and roof grouting as the supplement support are used in dangerous areas to reinforce the top coal crack, improve the integrity of the weak roof, and realize the three-dimensional compression of the coal and rock mass. (3) The high-strength I beam is selected to replace the w-steel tape for the roof near to N0381 gob. By improving roof surface confining pressure, the damage of high stress to the coal mass is reduced, and the self-supporting ability of the rock stratum is brought into play so that the supporting structure and surrounding rock work in harmony.

5.2.3. Reasonable Choice for Control Strategy of the Retracement Channel. Under the conditions of close-distance double-thick coal seams mining, the control strategy for the lower retracement channel is not a single type, but should be flexibly adjusted according to the stress state of the upper coal pillar, the severity of the mining dynamic pressure, and the failure characteristics of the surrounding rock. According to local models, the stress concentration in the unstable coal pillar $(w / h=1)$ is lesser than in situ stress, which has almost no impact on the retracement channel. Therefore, the control strategy only needs to consider the asymmetric strata behavior caused by mining dynamic pressure, and the support design can be carried out with "asymmetric high- strength cable-beam net." When the upper coal pillar is in the critical stable state $(w / h=2)$, high stress concentration is formed in the coal pillar. In view of this, the "highpressure water jet + asymmetric high-strength cable-beam net" should be adopted. When the upper coal pillar is in the stable state $(w / h>3)$, the high-pressure water jet is not a good way due to the large size of the upper coal pillar, and the partition control strategy with "asymmetric highstrength cable-beam net + three-hole anchor cable group + roof grouting" becomes an effective method to realize the stability of the surrounding rock.

5.3. Optimization of the Support Scheme for N0381 Retracement Channel. Based on the above analysis, the partition control strategy with "asymmetric high-strength cablebeam net + three-hole anchor cable group + roof grouting" as the core is put forward for N0381 retracement channel. According to the global model with the upper coal-pillar aspect ratio of 5, the plastic depth of the roof near to N0381 gob is over $7.0 \mathrm{~m}$; thus, the $6300 \mathrm{~mm}$-long anchor cable used in the previous support scheme is unreasonable. Due to hydraulic supports need to be transported along the virgin coal rib, the anchor cable in the roof near to the virgin coal rib should also be strengthened. The optimized support design not only lengthens the anchor cable, but also increases support density. In addition, three-hole anchor cable group and roof grouting as the supplement support are used in dangerous areas $(15 \sim 37 \mathrm{~m}$ away from N0481 tailgate; $58 \sim 83 \mathrm{~m}$ away from N0481 tailgate). The specific support parameters are shown in Figure 16. 

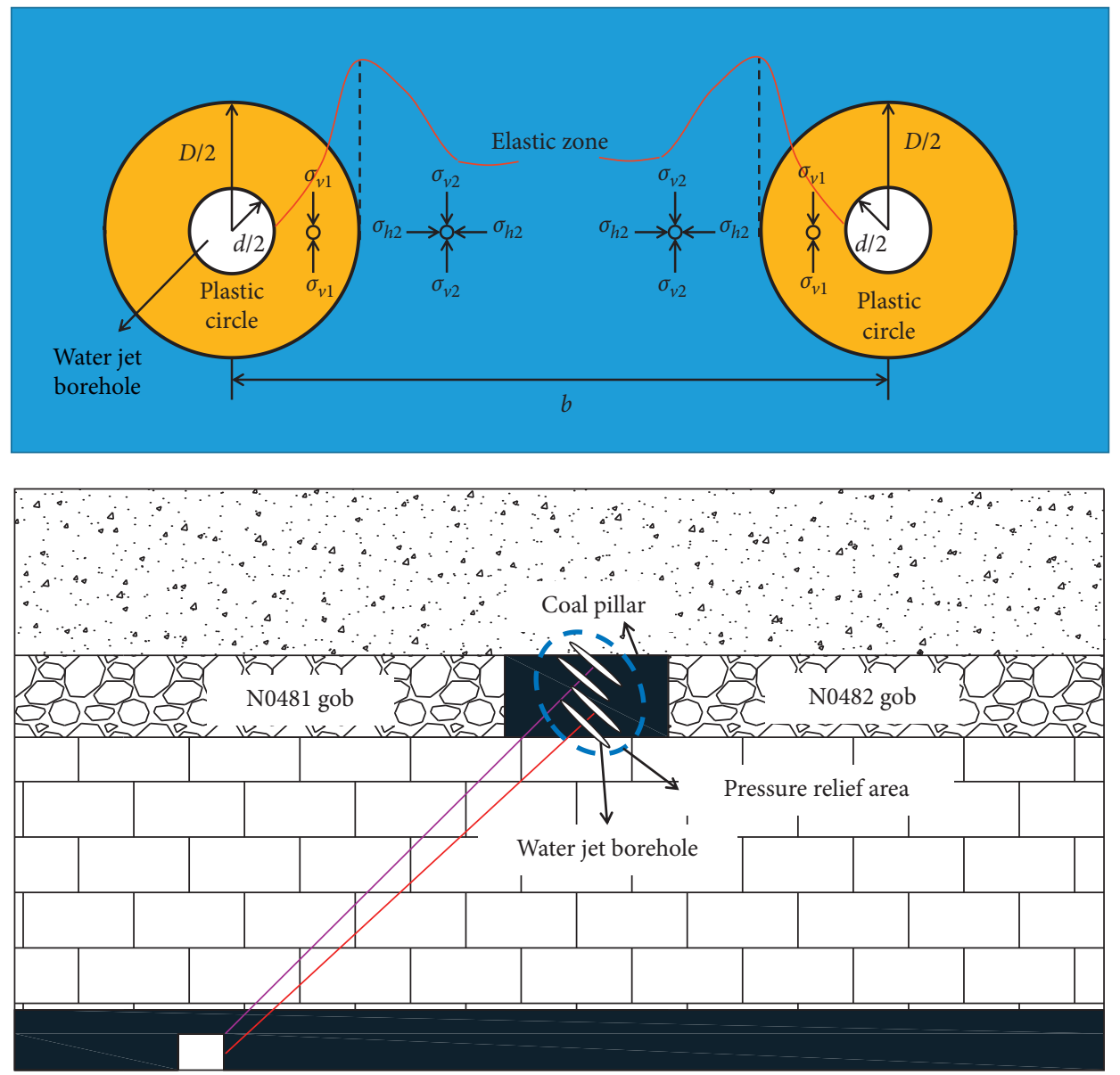

N0381 tailgate

N0381 working face

Figure 15: High-pressure water jet technology schematic.

Anchor cable $\varphi 21.8 \quad$, Three holes anchor cable group:

$\times 10300 \mathrm{~mm}$

Spacing: $1500 \mathrm{~mm}$

W-steel tape

$3500 \times 280 \times 4 \mathrm{~mm}$

Anchor bolt $\varphi 20 \times 2400 \mathrm{~mm}$

Spacing: $1500 \mathrm{~mm}$

$\mathrm{W}$-steel tape

$3 \underline{3500} \times \underline{2} 280 \times \underline{4} \mathrm{~mm}_{-}-{ }_{300}$

Anchor bolt $\varphi 18 \times 1700 \mathrm{~mm}$, 。

Spacing: $1500 \mathrm{~mm} \longrightarrow$

W-steel tape $400 \times 220 \times 3 \mathrm{~mm}^{\prime}$ \&

$\varphi 17.8 \times 8300 \mathrm{~mm}$
(9) (7) (7)

Combination plate $600 \times 600 \times 16 \mathrm{~mm}$

- - - - . - -

(5) (4) (3) (2) (1) Anchor cable $\varphi 17.8 \times 8300 \mathrm{~mm}$ ' Spacing: $1500 \mathrm{~mm}$

, 11 \# I beam $\mathrm{L}=4000 \mathrm{~mm}$

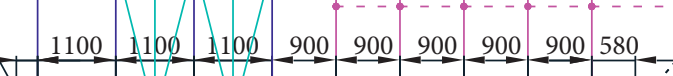

Double-steel mesh

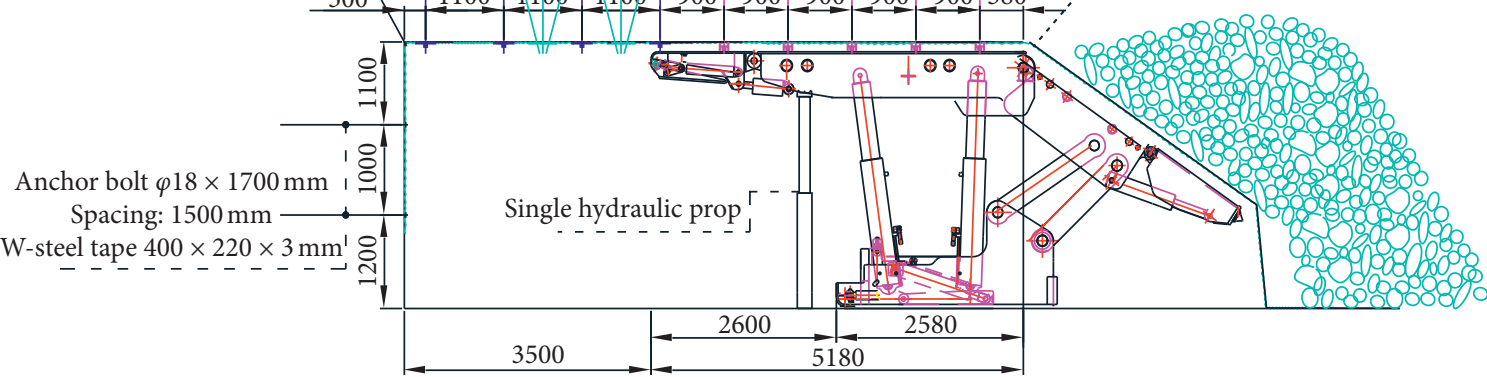

FIgURE 16: Optimized support scheme of N0381 retracement channel. 


\section{Conclusion}

This study provides a numerical simulation method for obtaining the failure characteristics of the lower retracement channel in close-distance double-thick coal seams. Compared with previous studies, this study has the following characteristics: (a) a local model with the strain-softening constitutive model was built to simulate the correlation between the stress concentration and the aspect ratio of the coal pillar; (b) based on the local model, a global model was built to simulate the failure mechanism of N0381 retracement channel under the double disturbance of upper coal-pillar static load and mining dynamic pressure; (c) theoretical prediction and field measurement were used to validate the local model and its input parameters, and the double-yield constitutive model used in N0381 gob was validated by comparing the simulation results from local and global models. The main conclusions are as follows:

(1) The local models show that there is a critical value $(w / h=2)$ for the coal pillar aspect ratio. When the size of the coal pillar is lower than the critical value, the coal pillar will be in the unstable state, and its stress concentration is lesser than in situ stress; when the size of the coal pillar is greater than or equal to the critical value, the coal pillar is in the critical stable or stable state, and its stress concentration slightly decreases as the aspect ratio increases.

(2) The global models show that the plastic failure and stress distribution of N0381 retracement channel are asymmetric evidently; specifically, the closer the roof is to N0381 gob, the stronger the strata behavior is. In addition, when the upper coal pillar is in the critical stable or stable state $(w / h>2)$, there are two dangerous areas formed in the retracement channel, and the strata behavior in those areas is more serious and shows stronger asymmetry.

(3) According to the failure mechanism of the surrounding rock, this study proposes a partition control strategy with "high-pressure water jet+ asymmetric high-strength cable-beam net + three-hole anchor cable group + roof grouting" as the core to realize the stability of the lower retracement channel. Moreover, the control strategy is not immutable, but should be flexibly adjusted according to the stress state of the upper coal pillar, the severity of mining dynamic pressure, and the failure characteristics of the surrounding rock.

\section{Data Availability}

The data used to support the findings of this study are included within this paper.

\section{Conflicts of Interest}

The authors declare that they have no conflicts of interest.

\section{Acknowledgments}

This work was supported by the National Natural Science Foundation of China (no. 51974317), Yue Qi Distinguished Scholar Project (800015Z1138), China University of Mining and Technology, Beijing, and Fundamental Research Funds for the Central Universities (2020YJSNY03).

\section{References}

[1] J. Guo, G. R. Feng, P. F. Wang, T. Y. Qi, X. R. Zhang, and Y. G. Yan, "Roof strata behavior and support resistance determination for ultra-thick longwall top coal caving panel: a case study of the Tashan coal mine," Energies, vol. 11, no. 5, pp. 1-19, 2018.

[2] D. Cao, A. Wang, S. Ning et al., "Coalfield structure and structural controls on coal in China," International Journal of Coal Science \& Technology, vol. 7, no. 2, pp. 220-239, 2020.

[3] L. Shao, X. Wang, D. Wang et al., "Sequence stratigraphy, paleogeography, and coal accumulation regularity of major coal-accumulating periods in China," International Journal of Coal Science \& Technology, vol. 7, no. 2, pp. 240-262, 2020.

[4] G. C. Zhang, Z. J. Wen, S. J. Liang et al., "Ground response of a gob-side entry in a longwall panel extracting $17 \mathrm{~m}$-thick coal seam: a case study," Rock Mechanics and Rock Engineering, vol. 53, no. 9, pp. 497-516, 2020.

[5] G. C. Zhang, Y. L. Tan, S. J. Liang, and H. G. Jia, "Numerical estimation of suitable gob-side filling wall width in a highly gassy longwall panel," International Journal of Geomechanics, vol. 18 , no. 8, 2018.

[6] J. Zhao, "Bolt support technology for large cross section equipment remove gateway and application," Coal Science and Technology, vol. 33, no. 11, pp. 5-7, 2005, in Chinese.

[7] B. Wang, F. Dang, W. Chao, Y. Miao, J. Li, and F. Chen, "Surrounding rock deformation and stress evolution in predriven longwall recovery rooms at the end of mining stage," International Journal of Coal Science \& Technology, vol. 6, no. 4, pp. 536-546, 2019.

[8] H. W. Lv, "The mechanism of stability of pre-driven rooms and the practical techniques," Journal of China Coal Society, vol. 39, no. S1, pp. 50-56, 2014, in Chinese.

[9] X. G. Ma, M. C. He, Y. J. Wang, Y. Zhang, J. B. Zhang, and Y. X. Liu, "Study and application of roof cutting pressure releasing technology in retracement channel roof of Halagou 12201 working face," Mathematical Problems in Engineering, vol. 2018, Article ID 6568983, 15 pages, 2018.

[10] L. Fei and Z. X. Jiang, "Research on deformation mechanism of retracement channel during fully mechanized caving mining in superhigh seam," Advances in Civil Engineering, vol. 2018, Article ID 1368965, 13 pages, 2018.

[11] J. H. Xu, X. X. Miao, A. H. Lu, and C. Q. Xing, "Stability analysis and support study on surroundings of finishing cut," Journal of China University of Mining \& Technology, vol. 32, no. 5, pp. 16-20, 2003, in Chinese.

[12] J. H. Xu, X. X. Miao, H. Pu, and S. G. Cao, "Determination of reasonable position and stability analysis of finishing cut in fully-mechanized coal face with topped caving," Chinese Journal of Rock Mechanics and Engineering, vol. 2004, no. 12, pp. 1981-1985, 2004, in Chinese.

[13] C. X. Shu, F. X. Jiang, Y. Y. Han et al., "Long-distance multicrosscut rapid-retracement technique in deep heavy fully mechanized face," Journal of Mining \& Safety Engineering, vol. 35, no. 3, pp. 473-480, 2018, in Chinese. 
[14] D. Y. Hao, Y. Z. Wu, H. J. Chen, X. W. Chu, and Y. Li, "Instability mechanism and prevention technology of roadway in close distance and extra thick coal seam under goaf," Journal of China Coal Society, vol. 44, no. 9, pp. 2682-2690, 2019, in Chinese.

[15] X. Sun, Y. Liu, J. Wang, J. Li, S. Sun, and X. Cui, "Study on three-dimensional stress field of gob-side entry retaining by roof cutting without pillar under near-group coal seam mining," Processes, vol. 7, no. 9, pp. 1-30, 2019.

[16] C. Zhu, Y. Yuan, Z. S. Chen, Z. H. Liu, and C. F. Yuan, "Study of the stability control of the rock surrounding double-key strata recovery roadways in shallow seams," Advances in Civil Engineering, vol. 2019, Article ID 9801637, 21 pages, 2019.

[17] S. C. Gu, B. N. Wang, R. B. Huang, and Y. P. Miao, "Method for determining the load on and width of coal pillar at the recovery room end of fully mechanized longwall mining," Journal of China University of Mining \& Technology, vol. 44, no. 6, pp. 990-995, 2015, in Chinese.

[18] M. Li, J. X. Zhang, F. Ju, S. W. Liu, and Y. W. Cao, "Study on surrounding rock deformation control of finishing cut in backfilling mining face," Journal of Mining \& Safety Engineering, vol. 33, no. 4, pp. 699-705, 2016, in Chinese.

[19] S.-L. Wang, S.-P. Hao, Y. Chen, J.-B. Bai, X.-Y. Wang, and $\mathrm{Y}$. $\mathrm{Xu}$, "Numerical investigation of coal pillar failure under simultaneous static and dynamic loading," International Journal of Rock Mechanics and Mining Sciences, vol. 84, pp. 59-68, 2016.

[20] S. H. Prassetyo, M. A. Irnawan, G. M. Simangunsong, R. K. Wattimena, I. Arif, and M. A. Rai, "New coal pillar strength formulae considering the effect of interface friction," International Journal of Rock Mechanics and Mining Sciences, vol. 123, pp. 1-19, 2019.

[21] P. Sharma, A. K. Verma, and P. Gautam, "Stability analysis of underground pillar in the presence of overlying dump: a case study," Arabian Journal of Geosciences, vol. 13, no. 5, pp. 1-13, 2020.

[22] T. Hauquin, O. Deck, and Y. Gunzburger, "Average vertical stress on irregular elastic pillars estimated by a function of the relative extraction ratio," International Journal of Rock Mechanics and Mining Sciences, vol. 83, pp. 122-134, 2016.

[23] M. D. G. Salamon, I. Canbulat, and J. A. Ryder, "Seam-specific pillar strength formulae for South African collieries," in Proceedings: the 41st US Symposium on Rock Mechanics, Golden, Colorado, June 2006.

[24] Z. T. Bieniawski, "In situ strength and deformation characteristics of coal," Engineering Geology, vol. 2, no. 5, pp. 325-340, 1968.

[25] G. M. Mohan, P. R. Sheorey, and A. Kushwaha, "Numerical estimation of pillar strength in coal mines," International Journal of Rock Mechanics \& Mining Sciences, vol. 38, no. 8, pp. 1185-1192, 2001.

[26] E. Esterhuizen, C. Mark, and M. M. Murphy, "Numerical model calibration for simulating coal pillars, gob and overburden response," Source," in Proceedings-29th International Conference on Ground Control in Mining, ICGCM, pp. 46-57, Canonsburg, PA, USA, July 2010.

[27] T. P. Medhurst and E. T. Brown, "A study of the mechanical behaviour of coal for pillar design," International Journal of Rock Mechanics and Mining Sciences, vol. 35, no. 8, pp. 1087-1105, 1998.

[28] W. R. He, F. L. He, and Y. Q. Zhao, "Field and simulation study of the rational coal pillar width in extra-thick coal seams," Energy Science \& Engineering, vol. 8, no. 3, pp. 627-646, 2020.
[29] Q. S. Li, Z. H. Xu, Y. Zhang, and W. R. He, "Study on deformation and failure characteristics of overlying strata with thick loose layers and thin bedrock based on Hoek-Brown criterion," Journal of Mining Science and Technology, vol. 4, no. 5, pp. 417-424, 2019, in Chinese.

[30] E. Hoek and E. T. Brown, "The Hoek-Brown failure criterion and GSI-2018 edition," Journal of Rock Mechanics and Geotechnical Engineering, vol. 11, no. 3, pp. 445-463, 2019.

[31] L. Jiang, A. Sainoki, H. S. Mitri, N. Ma, H. Liu, and Z. Hao, "Influence of fracture-induced weakening on coal mine gateroad stability," International Journal of Rock Mechanics and Mining Sciences, vol. 88, pp. 307-317, 2016.

[32] C. Mark and F. E. Chase, "Analysis of retreat mining pillar stability," in Proceedings: New Technology for Ground Control Retreat Mining-NIOSH IC 9446, pp. 17-34, Pittsburgh, PA, USA, March 1997.

[33] A. Kushwaha and G. Banerjee, "Exploitation of developed coal mine pillars by shortwall mining - a case example," International Journal of Rock Mechanics \& Mining Sciences, vol. 42, no. 1, pp. 127-136, 2005.

[34] S. T. Gu, B. Z. Wei, B. Y. Jiang, and L. H. Tai, "Stability analysis of irregular coal pillars in bilateral goaf," Safety in Coal Mines, vol. 51, no. 3, pp. 216-220, 2020, in Chinese.

[35] L. S. Jiang, Q. S. Wu, X. Y. Li, and N. Ding, "Numerical simulation on coupling method between mining-induced stress and goaf compression," Journal of China Coal Society, vol. 42, no. 8, pp. 1951-1959, 2017, in Chinese.

[36] G. R. Feng and P. F. Wang, "Stress environment of entry driven along gob-side through numerical simulation incorporating the angle of break," International Journal of Mining Science and Technology, vol. 30, pp. 189-196, 2020.

[37] M. D. G. Salamon, "Mechanism of caving in longwall coal mining," in Rock Mechanics Contributions and Challenges: Proceedings of the 31st US Symposium, pp. 161-168, Golden, CO, USA, June 1990.

[38] H. Yavuz, "An estimation method for cover pressure reestablishment distance and pressure distribution in the goaf of longwall coal mines," International Journal of Rock Mechanics and Mining Sciences, vol. 41, no. 2, pp. 193-205, 2004.

[39] M. Z. Li, Z. M. Ma, D. L. Xue, and Y. H. Yuan, "Research of cumulative energy blasting technology with deep and shallow hole combined in hard roof," Journal of Mining Science and Technology, vol. 5, no. 6, pp. 616-623, 2020, in Chinese.

[40] Y. B. Wang, B. B. Yu, J. Kong, Z. Y. Wang, and H. W. Wu, "Methods and devices for evaluation of blasting damage to indoor small quantity rock," Journal of Mining Science and Technology, vol. 5, no. 6, pp. 624-631, 2020, in Chinese.

[41] J. Wang, J. Yang, F. Wu, T. Hu, and S. A. Faisal, "Analysis of fracture mechanism for surrounding rock hole based on water-filled blasting," International Journal of Coal Science \& Technology, vol. 7, no. 4, pp. 704-713, 2020. 